\title{
Interannual signals in length of day and atmospheric angular momentum
}

\author{
R. Abarca del Rio ${ }^{1}$, D. Gambis ${ }^{2}$, D. A. Salstein ${ }^{3}$ \\ ${ }^{1}$ Spaceflight Dynamics Department, CS, 13 rue Villet - ZI du Palays BP 4042-31029 Toulouse Cedex 4-France \\ E-mail: Rodrigo.Abarca-del-Rio@cisi.cnes.fr \\ ${ }^{2}$ International Earth Rotation Service, (IERS), URA1125, Observatoire de Paris, 61 Av. de l'Observatoire, Paris, France \\ ${ }^{3}$ Atmospheric and Environmental Research, Inc., 840 Memorial Drive, Cambridge, MA 02139-3794, USA
}

Received: 23 September 1998 / Revised: 8 November 1999 / Accepted: 15 November 1999

\begin{abstract}
Atmospheric angular momentum (AAM) and length of day (LOD) series are investigated for their characteristics on interannual time scales during the half-century period 1949 to 1998 . During this epoch, the interannual variability in LOD can be separated naturally into three bands: a quasi-biennial, a triennialquadrennial and one at six-seven years. The atmosphere appears to excite the first two bands, while it does not contribute to the last. Considering the quasi-biennial (QB) band alone, the atmosphere appears to excite most of its signal in LOD, but it arises from separate fluctuations with stratospheric and tropospheric origin. Thus, although close in frequency, stratospheric and tropospheric processes differ in their amplitude and phase variability. The time shift can be noted especially during the strong El Niño events of 1982-83 and 199798 when both processes have positive phase and thus combine to help produce particularly strong peak in AAM and LOD. In addition, we have reconfirmed the downward propagation in the stratosphere and upward propagation in the troposphere of AAM observed in earlier studies for other variables. In the triennialquadrennial (TQ) band, time-variable spectral analyses reveal that LOD and AAM contain strong variability, with periods shorter than four years before 1975 and longer thereafter. This signal originates mainly within the troposphere and propagates upwards from the lower to the higher layers of the troposphere. According to a zonal analysis, an equatorial poleward mode, strongly linked to the SOI, explains more than $60 \%$ of the total variability at these ranges. In addition, this study also indicates that an equatorward mode, originating within polar latitudes, explains, on average, more than $15 \%$ of the triennial-quadrennial oscillation (TQO) variability in AAM, and up to $30 \%$ at certain epochs. Finally, a six year period in LOD noted in earlier studies, as well as in lengthier series covering much of the century, is found to be absent in atmospheric excitations, and it is thus likely to arise from mantle/core interactions.
\end{abstract}

Correspondence to: R. Abarca del Rio
Key words: Meteorology and atmospheric dynamics (general circulation) - Solar physics, astrophysics and astronomy (celestial mechanics)

\section{Introduction}

Atmospheric angular momentum (AAM) as a fundamental geophysical parameter, measures the intensity of the zonal circulation. Its maintenance against dissipation has long been at the forefront of meteorological research. Starr (1948) recognises that conservation of the angular momentum in the solid Earth-atmosphere system, would require than an increase in AAM be accompanied by a decrease in the rotation rate of the Earth and hence an increase in the length of day (LOD).

Small fluctuations in the LOD, which were only inferred indirectly on the basis of positional astronomy several decades ago (e.g. Stephenson and Morrison, 1995), have become more accurately measured since the introduction of the atomic clock. The precision has improved even more dramatically since the advent of space-based measurements in the 1970s. Thus, measurements of LOD exhibits variations of a few milliseconds on time scales from days to years, whose precision has improved continually in times to $0.02 \mathrm{~ms}$ for the present values (IERS, 1998). Contemporary reviews of the variation in the Earth's rotation and its connection with atmospheric processes has been given by Wahr (1980), Hide and Dickey (1991), Rosen (1993) and Eubanks (1993).

The impact of the atmosphere on the rotation of the Earth can be studied by two conceptually related but different approaches: by calculating the torques that dynamically exchange angular momentum between components, and by studying the balance of the angular momentum itself. In the torque approach, normal pressure gradient forces and tangential stresses exert on the Earth's surface, and body gravitational forces exert additional body torques, though of considerable 
smaller amplitude. Such torques may be related to both the Earth's and atmosphere's rate of change of angular momentum, which in a closed system would be equal and opposite. The equivalence of these approaches has been described by Munk and MacDonald (1960) and Lambeck (1980), and highlighted recently by DeViron et al. (1999). The excitation functions for the torque approach, however, are complex, and, moreover, cannot be evaluated simply from routine meteorological data, since stresses must be estimated principally through atmospheric modelling (Wahr and Oort, 1983). However, Barnes et al. (1983) direct treatment of the excitation functions for the angular momentum approach introduces the effective atmospheric angular momentum (EAAM) functions which can be evaluated from routine meteorological data (Salstein et al., 1993). The relation between LOD variability and that of AAM is a direct proportionality given the assumption that the solid Earth and atmosphere form a closed dynamic system. This excitation includes effects of motion and mass in the following two integrals, respectively (Barnes et al., 1983)

$$
\begin{aligned}
\Delta \mathrm{LOD} \cong & \frac{R^{3}}{C \Omega g} \int_{0}^{P_{S}} \int_{-\pi / 2}^{\pi / 2} \int_{0}^{2 \pi} u \cos ^{2} \varphi \partial \lambda \partial \varphi \partial p \\
& +\frac{0.70 R^{4}}{C g} \int_{-\pi / 2}^{\pi / 2} \int_{0}^{2 \pi} p_{s} \cos ^{3} \varphi \partial \lambda \partial \varphi
\end{aligned}
$$

Here $R$ is the radius of the Earth, $C$ the principal moment of inertia of Earth's mantle plus crust, $\Omega$ the mean rate of rotation of the Earth, $g$ the acceleration due to gravity, $p_{s}$ atmospheric surface pressure and $u$ the zonal winds. In the motion part, the dominant term on most time scales, the zonal winds are integrated over all latitudes, $\varphi$, longitudes, $\lambda$, and pressures, $p$. The second term, related to changes in the mass distribution of the atmosphere by using the surface pressure values, plays a much smaller role in LOD variations on most time scales, because of the relatively stable zonal mean pressure distribution and therefore it is not considered in what follows. The influence of other geophysical fluids are also assumed to be unimportant here.

The AAM and LOD series have clear variability at interannual time scales (Eubanks, 1993), with an important process on these scales recognised to be associated with El Niño/Southern Oscillation (ENSO) phenomena, as investigated first by Stefanick (1982) and Chao (1984). Another well-known source of variability is associated with the atmospheric quasi-biennial oscillation (QBO), a signal with a somewhat variable period about two-year (Trenberth, 1980). However, despite the known existence of zonal winds alternations with nearbiennial scales in the equatorial stratosphere and observations with the same periodicity in surface parameters (Landsberg, 1962), quasi-biennial (QB) signals in Earth rotation were not detected until Iijima and Okazaki (1966). Later, Chao (1989) related Earth rotation to a combination of two interannual signals, those of the
Southern Oscillation (SO) and the stratospheric quasibiennial oscillation (S-QBO); both atmospheric phenomena were required to explain the major interannual variability in LOD.

The atmospheric component of ENSO, the Southern Oscillation, is one of the prominent climate anomalies in the equatorial atmosphere. It is characterised by alternate variation of sea level pressure anomalies of opposite signs on either side of the tropical Pacific. This variation is mutually coupled with sea surface temperature (SST) variations particularly with warm SST anomalies in the central and eastern Pacific, known as El Niño events. As an index representing this fluctuation, the Southern Oscillation index (SOI) which is a relative measure of the pressure gradient between Tahiti $\left(18^{\circ} \mathrm{S}, 150^{\circ} \mathrm{W}\right)$ and Darwin $\left(12^{\circ} \mathrm{S}, 131^{\circ} \mathrm{E}\right)$, is used. During El Niño events, when the SOI has large negative values, there are positive pressure anomalies in the western Pacific and negative anomalies in the eastern Pacific, resulting in an anomalously positive eastward gradient of the pressure field, decreasing the normal easterly wind, and increasing AAM (Stefanick, 1982). Here we use a modified SOI (MSOI), following Chao (1984), i.e. the inverted index (the index multiplied by negative one), for comparative studies with AAM or other related parameters.

The QBO was well known in the atmosphere long before ENSO became a principal focus of studies of interannual variability. However, we should distinguish between the stratospheric and the tropospheric part of the QBO (S-QBO and T-QBO respectively), since it is still not yet clear if a relationship exist between both.

The QBO in the upper atmosphere has been studied since its independent discovery by Reed et al. (1961) and Veryard and Ebdon (1961). The S-QBO is the most prominent feature in the variability of the equatorial middle and lower stratospheric circulation between 70 and $10 \mathrm{hPa}$. The $\mathrm{S}-\mathrm{QBO}$ is characterised by the alternating downward propagation of easterly and westerly wind regimes repeating at quasi-regular intervals of about 27-28 months (Fraedrich et al., 1993). During half the period, easterlies propagate from the upper stratosphere to the lower stratosphere, and during the other half they are replaced by westerly winds. Both descend at an average rate of about $0.7 \mathrm{~km} / \mathrm{mo}$, but the westerlies descend somewhat faster. Both the amplitude and period of the S-QBO are observed to vary from one cycle to the next (e.g. Quiroz, 1981; Angell, 1986; Sasi and Krishna Murthy, 1991), with periods ranging from 22 to 34 months, and maximum peak-to-peak amplitude at about $20 \mathrm{~m} / \mathrm{s}$ near 20-30 hPa (see Naujokat, 1986; Swinbank and O'Neill, 1994). Holton and Lindzen (1972) have explained the S-QBO by processes of momentum deposition due to selective absorption by the stratosphere of tropospheric eastward-propagating Kelvin waves (which gives a westerly acceleration) and westward-propagating Rossby-gravity waves (which give an easterly acceleration). The waves are absorbed in regions of increasing westerlies and easterlies, respectively, causing the wind regimes to descend with time. However, although the theory can explain the time 
evolution and the vertical structure of the S-QBO, until now no 3D model has been able to reproduce correctly all their characteristics (see Takahashi, 1996; Geller et al., 1998).

On the other hand, the tropospheric quasi-biennial oscillation (T-QBO) has been clearly seen in tropical meteorological radiosonde data since the early 1950s, and there is indirect evidence that it has been present in varying degrees since at least the 1880s (see Landsberg, 1962). For example, biennial variability in the SO was first noted by Berlage $(1955,1957)$. Since then the $\mathrm{T}-\mathrm{QBO}$ has been indicated in many climatic indices (see Trenberth, 1980). It is now established that it is a remarkably persistent phenomenon; it is a linear climate signal in the tropics, strongly linked with ENSO as well as the annual cycle (Lau and Sheu, 1988; Barnett, 1991), that seems not to need an external forcing or association with the stratospheric variability to be generated (Goswani, 1995). Furthermore, the study of $\mathrm{Xu}$ and Storch (1990) showed that the quasi-biennial cycle is the dominant mode of the $\mathrm{SO}$, and a prediction scheme based on this cycle is skillful in describing and forecasting the SO variability.

Due to the importance of ENSO phenomena, and to the pair of tropospheric and stratospheric quasi-biennial oscillations, a linear link between the S-QBO and the SO processes has been intensely investigated. However, although some studies (Gutzler and Harrison, 1987; Yasunari, 1989; Barnston et al., 1991; Gray et al., 1992; Angell, 1992; Sasi, 1994; Baldwin and Sullivan, 1995) suggest that a possible but yet uncertain relationship may exist between the S-QBO and ENSO, the evidence that is available is far from convincing. Other studies (e.g. Trenberth, 1980; Quiroz, 1983; Barnett, 1989, 1991; Xu, 1992) have been negative or inconclusive on a linear relationship. Moreover, while the S-QBO has no clear zonal structure, the T-QBO presents a zonal structure with eastward phase propagation (Trenberth, 1975; Ropelewski et al., 1992). Furthermore, it is not clear whether there is only one or multiple QBO signals in the troposphere (Trenberth, 1980; Rasmusson et al., 1990).

In addition, while the QBO appears to be a fundamental mode of the stratospheric variability, the SO occurs on more than one interannual time scale, that, moreover, may be modulated interdecadally (Wang and Wang, 1996), and contains also an apparent decadal variability (Brassington, 1997; Zhang et al., 1997). However, the dominant interannual variability is associated with both quasi-biennial and a quadrennial year periods, which, when added constructively contribute significantly in making an ENSO event particularly strong (Yasunari, 1985; Barnett, 1991).

Investigating AAM in zonal belts for the period 1976-1991, Dickey et al. (1992) showed that the AAM over the troposphere contained propagating poleward modes at two particular periods of 2.3 and 4.2 years. The constructive addition of these modes, similar to the case of the SO (Yasunari, 1985; Barnett, 1991), produce a strong El Niño signal in AAM and LOD. This split time scale for the AAM variability was analysed as well by Black et al. (1996) for the longer period 1963-1989 using an alternate rawinsonde-based and operational dataset.

Thus, interannual fluctuations in LOD appear to be mainly of atmospheric origin and highly related to the ENSO variability. However, a six-year oscillation (SYO) in LOD, identified at least as long ago as Vondrak (1977), and readdressed recently by Djurovic and Pâquet (1996), appears to be present in the LOD series, though not mirrored in AAM series; in this case it was considered likely to be connected to geomagnetic or solar forcing.

Because a modern, increasingly accurate geodetic data set span now about more than four decades, and taking advantage of a relatively homogeneous atmospheric data set based on the reanalyses from the US National Centers for Environmental Prediction/National Center for Atmospheric Research (NCAR/NCEP; Kalnay et al., 1996) to calculate atmospheric angular momentum for the last half-century (Salstein and Rosen, 1997), we will use both sets between 1949 and 1998 , to reexamine balances in the Earth-atmosphere momentum budget at periods greater than a year. Additionally, we extend the analysis by investigating interannual variability in LOD over more than a century. An additional goal is to investigate the overall vertical and meridional variability related to the $\mathrm{QBO}$ and TQO time scales, in order to describe the atmospheric modes participating in LOD fluctuations. This work will therefore extend, in both time and scope, earlier works on the subject (Dickey et al., 1992; Black et al., 1996). The study will focus on interannual time scales and will not address longer or shorter angular momentum fluctuations. For recent results studies regarding seasonal time scales, information can be found in Höpfner (1998) and Marcus et al. (1998), and for momentum fluctuations at even higher frequencies, like the intraseasonal Madden-Julian oscillations, note Weickmann et al. (1997). On decadal and longer time scales, investigations by Greiner-Mai (1993), Jochmann and Greiner-Mai (1996), Greiner-Mai and Jochmann (1998) and Stephenson and Morrison (1995) are good examples.

The outline is as follows. Following a brief description of the data and methodology applied, the third section discusses interannual signals on six-year time scales in LOD that are not mirrored in the AAM variability. The fourth section describes common interannual variability in LOD and AAM, with subsections considering quasi-biennial variability and the triennial-quadrennial time scales. The fifth section extends and updates previous findings by Yasunari (1985), Barnett (1991), Dickey et al. (1992), Black et al. (1996) and recently by Dickey et al. (1999), regarding the interaction between quasi-biennial and quadrennial cycles in strong ENSO events. It also explains relationships between ENSO and LOD. The final sections discusses, concludes and summarises the results found, while it also addresses some further problems to be tackled. 


\section{Data and methodology}

The Earth rotation data used here are composite sets covering more than a century, derived from several universal time series (UT1-UTC): the lunar occultationbased series of Jordi et al. (1994) over 1850-1980, the Paris astrolabe derived series (Guinot, personal communication, 1996) over 1956-1962, and a combined series derived from both astrometric and space geodetic techniques since 1962 (IERS, 1998). The LOD series are determined as the time derivative of the composite UT1UTC series, over each of these time spans: 1850-1980, 1956-1962 and 1962-1998. Note that the precision of LOD data has improved dramatically in time, from $100 \mathrm{~ms}$ in 1850 to $0.02 \mathrm{~ms}$ for the most recent values. From these data we constructed two sets. The first set, LOD1, is sampled monthly from January 1949 to December 1998. The second set, LOD2, is seasonally sampled (four times a year), from spring 1850 to winter 1998.

Although a number of atmospheric angular momentum sets from operational analyses of the major centres is available (Bell and Nitsas, 1989; Salstein et al., 1993) as well as special rawinsonde-based data sets (Black et al., 1996; Abarca del Rio, 1997), these cover different lengths and depths within the atmosphere. Here we take advantage of the longer and homogeneous NCEP/ NCAR reanalyses that incorporate a wide variety of observations, assimilated through a global atmospheric model (Kalnay et al., 1996), and which spans the atmosphere up to $10 \mathrm{hPa}$ (approximately $33 \mathrm{~km}$ in altitude) (see Salstein and Rosen, 1997). We will also use estimates of the Southern Oscillation Index (SOI), given on a monthly basis from January 1949 to December 1998, to understand the relationship between AAM and the southern oscillation.

In as much as we are also concerned with the AAM contribution through the depth of the atmosphere as on zonal bands, we compute the relative AAM within each layer for which zonal winds were available, as over separate latitude bands. The manner by which these relative AAM products have been obtained are explained within Abarca del Rio (1997).

\section{A six year oscillation in the length of day signal}

The LOD1 time series, and the AAM series integrated up to $10 \mathrm{hPa}$, (hereafter $N C E P_{\mathrm{W}}^{10}$ ), extending from January 1949 to December 1998, are displayed in Fig. 1a. Both data sets then underwent a low pass filtering with a cut-off at 1.5 years ( 22 months), using a technique based on wavelets (Torrence and Compo, 1998) (Fig. 1b). To avoid wrap around effects, each time series is padded with zeroes (see Torrence and Compo, 1998). Here, in addition, in order to further minimise end effects, before any wavelets analysis, we extend the time series by $1 / 4$ their length on both their sides, using an ARMA forecast technique (Box and Jenkins, 1976).

Figure $1 \mathrm{~b}$ and the corresponding wavelet power spectrum (see Gambis, 1992; Torrence and Compo,
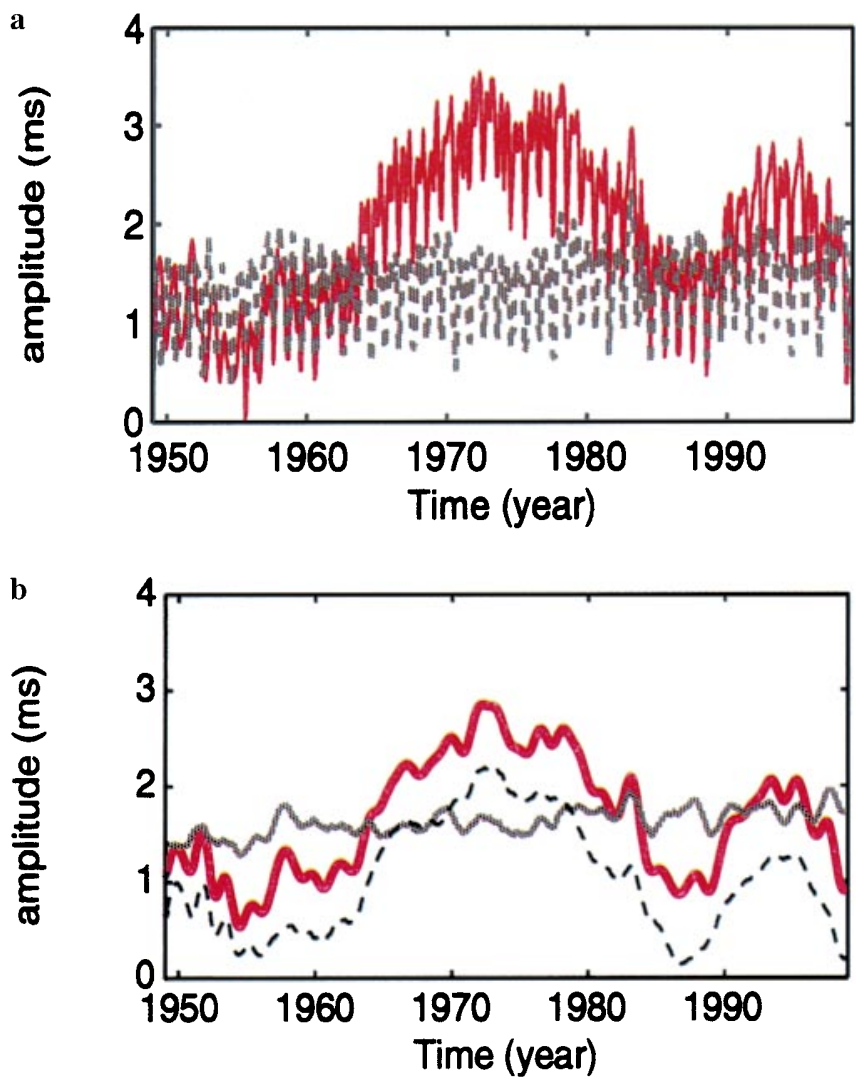

Fig. 1. a Unfiltered time series of LOD (solid red) and AAM (i.e. $N C E P_{\mathrm{W}}^{10}$ ) (dashed grey), b seasonally filtered time series of LOD (solid red), AAM (i.e. $N C E P_{\mathrm{W}}^{10}$ ) (solid grey) and the difference LOD-AAM (dashed). Units are in milliseconds (ms)

1998) on Fig. 2a, shows that the LOD series are dominated by powerful decadal and interdecadal modes, which are believed to be due to mantle-core interactions (Eubanks, 1993), as well as power at several interannual time scales. Although the power at interannual time scales is not always formally significant (see Torrence and Compo, 1998), at times the presence of broad bands increases confidence. The wavelet analysis presents a broad band period ranging from 5 to 8 years from 1950 to 1970 . We reconstructed all signals from 5.5 to 9.5 years (Fig. 3), using the wavelet-based, band pass filtering technique developed by Torrence and Compo (1998). The period ranges from about 6.5-7.7 years in 1949-1970 to 5.5-7 years in 1970-1990, and lower than seven years after.

We also made a straightforward Fourier analysis of the time series. We took a power spectrum (Rosen and Salstein, 1983) of the monthly-values series for LOD, AAM and their difference (LOD-AAM) between 1949 and 1998 using a single periodogram, restricted to signals longer than two years (Fig. 2b). Here we note the emergence of the QBO peak, somewhat longer than two years, a peak between three and four years, and a peak somewhat longer than six years. Whereas the QBO and the 3-4 year periods also have similar power in AAM, we note the absence of power in AAM at the peak near 6 years. To examine the peak centered at six years, which 

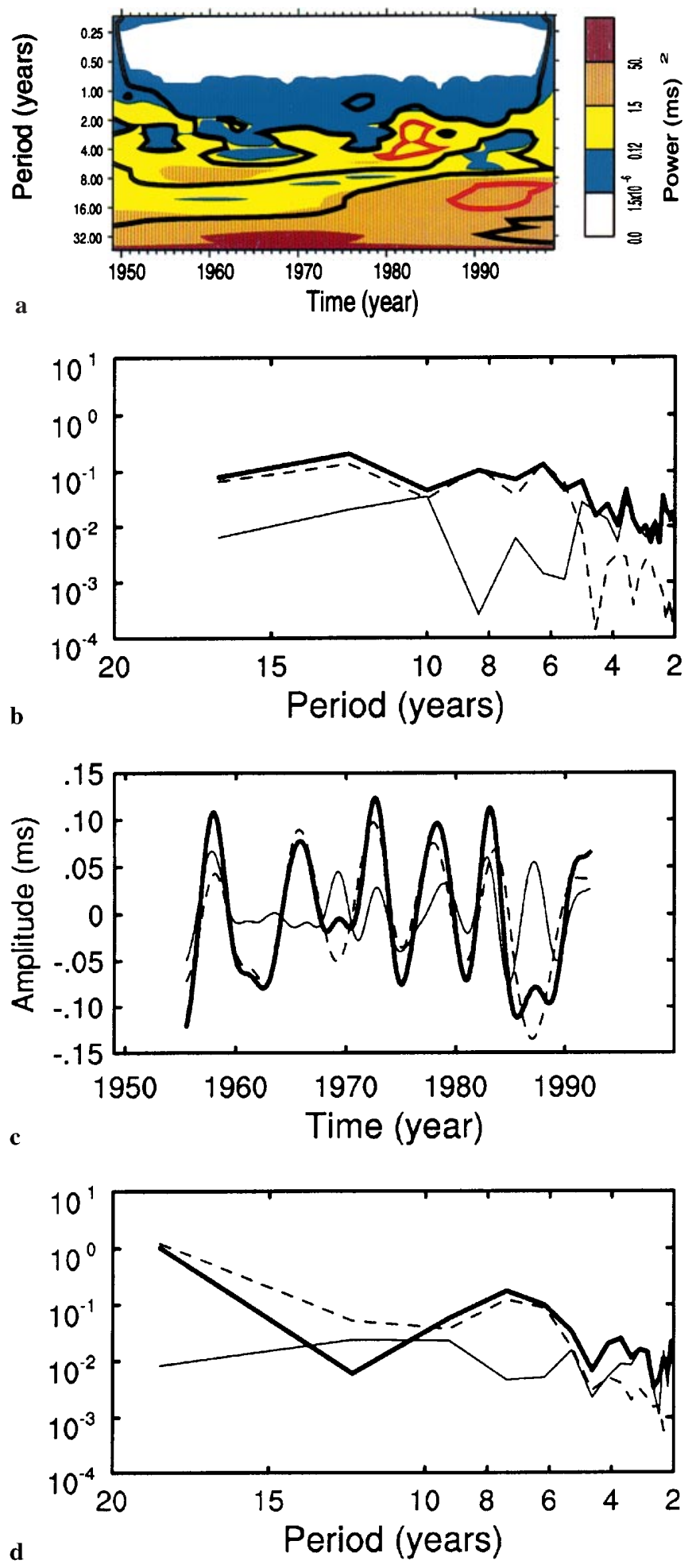

Fig. 2. a Wavelet power spectrum of the LOD time series. The contour levels are chosen so that $75 \%, 50 \%, 25 \%$ and $5 \%$ of the wavelet power is above each level, respectively. Black and red contours are the $50 \%$ and $90 \%$ significance level, using the global wavelet spectrum as the background. b Power spectral density, in units of $\mathrm{ms}^{2} /$ year, of LOD (solid bold line), AAM (light solid line), and the difference, LOD-AAM (dashed line), for the period 1949-1998, for interannual periods longer than 2 years. c Band-passed (between 5 and 8 years) series for LOD (solid bold curves), AAM (light solid curves) and the difference LOD-AAM (dashed curve). d Same as b, but restricted to data between 1949 and 1985

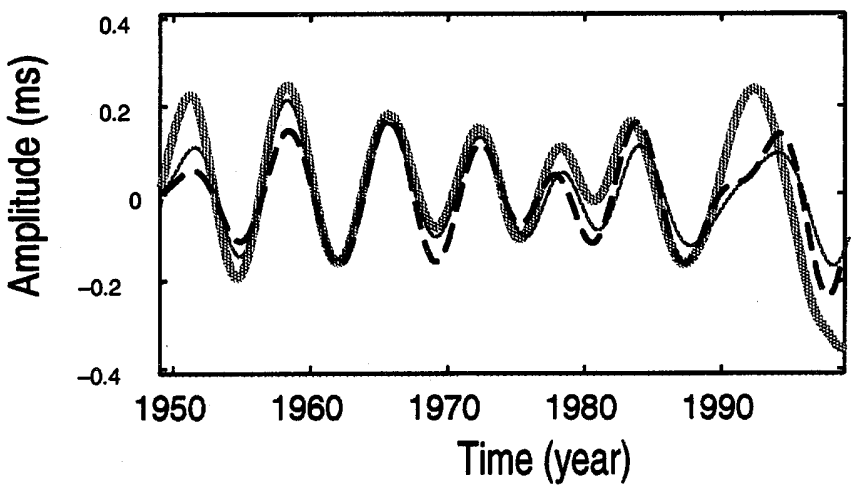

Fig. 3. Six-seven-year oscillation, obtained from a singular spectrum analysis (SSA) with an embedding dimension of 8 years (bold grey line). From a wavelet-based filter, 5.5 to 9 years on LOD (bold dashed line) and LOD-AAM difference (solid line)

is observed to be broadly powered between 5 and 8 years, we apply a band-pass filter to the three data sets in Fig. 2b. Although the data over 6.5 years at both end of the series must be removed due to requirements of this band-pass filter, we note in general that the LOD signal in this band is unmatched by AAM throughout most of the period. However, this lower frequency signal is particularly weak after 1985, suggesting further the application of the spectral analysis to the period 19491985 (Fig. 2d). The resulting spectra from this shortened period provide even clearer evidence of the importance of the 6-7 year peak in LOD, also completely unaccompanied by a comparable signal in AAM in that band.

A different technique is used for determining the veracity of the six-year oscillation (SYO). A singular spectrum analysis (SSA; Vautard and Ghil, 1989; Vautard et al., 1992; Dettinger et al., 1995a), with embedding dimensions (window length $M$ ) ranging from $M=60$ months (5 years) to $M=192$ months (16 years) $(<1 / 3$ the length of the series), was applied to the seasonally filtered LOD1 series in Fig. 1. In all analyses, at least two of the main components contain the 6-7 year period variability, explaining $3 \%$ to $4 \%$ of the total interannual-decadal-interdecadal variability. We show here the SSA analysis with an embedding dimension $M$ of 96 months (8 years). The first and second modes of this analysis (not shown) are related to decadal and interdecadal oscillations and explain $92.5 \%$ of the total variance. The reconstructed oscillation from the sum of the third and fourth modes, that explains $4 \%$ of the total interannual-decadal-interdecadal times scales in LOD (Fig. 1), is also present in Fig. 3.

The wavelet, Fourier, and SSA analyses, therefore, all corroborate each other, and substantially establish the presence of a 6 to 7 year oscillation in the LOD data.

Figure 1b (dashed line) also shows the difference between LOD1 and $N C E P_{\mathrm{W}}^{10}$ signals over 1949-1998. The amplitude diagram of the wavelet transform (see Abarca del Rio and Cazenave, 1994) of this difference (Fig. 4), shows that, for the most part, all interannual variations in LOD are explained by those in AAM, except for 


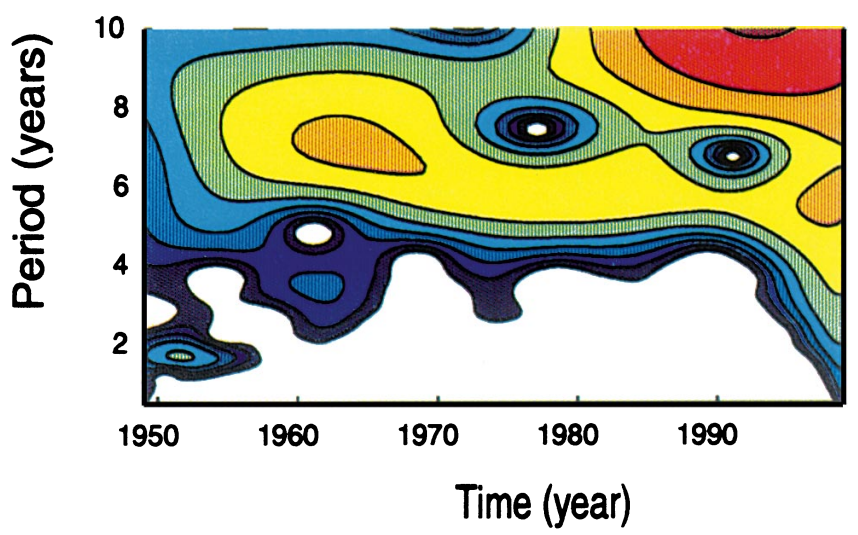

Fig. 4. Amplitude diagram of the wavelet transform of LOD- $N C E P_{\mathrm{W}}^{10}$ time series. Contour intervals at $0.025 \mathrm{~ms}$ intervals

those in the six to seven year period. The reconstructed signal from after band pass filtering from 5 to 9.5 years, applied to the difference series (LOD-NCEP $\left.P_{\mathrm{W}}^{10}\right)$, also presented in Fig. 3, reconfirms the Fourier band-pass filter results in Fig. 2c that this signal is not excited by the atmosphere.

After having established the reality of that period in LOD over 1949-1998, it is possible using the LOD2 data set series to investigate the SYO variability through the century. Although the quality of the LOD signal has increased considerably since the beginning of its measurements, from $2 \mathrm{~ms}$ in 1850 to almost $0.02 \mathrm{~ms}$ at present, the accuracy of its variability before 1956 is small, especially before the 1920s (Jordi et al., 1994). In Fig. 5 is shown the variability near the six year period obtained by two different methods, i.e. wavelets bandpass filtering (5.5 to 8 years) and the sum of third and fourth reconstructed modes for an SSA with a window of 8 years. Both methods do indicate the same phase variability, but differ in their amplitude before 1940 . This figure shows therefore that the SYO signal is present over most of the century, with an average amplitude of $0.12 \mathrm{~ms}$.

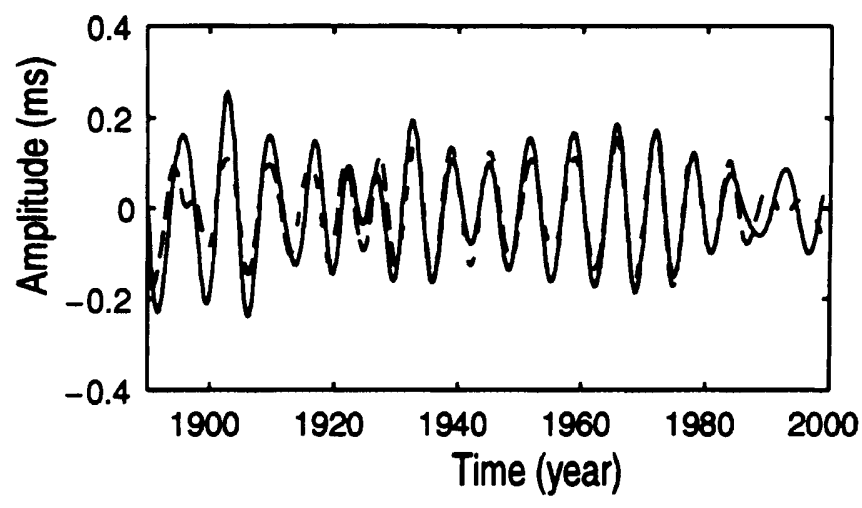

Fig. 5. Six to seven-year oscillation time series over the century, from a singular spectrum analysis (SSA) with an embedding dimension of 8 years (solid) and from a wavelet based filter, 5.5 to 8 years on LOD (dashed)

\section{Related variability in LOD and AAM}

In order to investigate the association between LOD and AAM series at interannual times scales, both series were band-pass filtered between 1.5 and 5 years, thereby avoiding seasonal effects and the 6-year period in LOD. End effects are attenuated by applying the same technique as in the precedent section. The series are shown in Fig. 6. Their Pearson product-moment correlation (Press et al., 1992) is 0.896 at a 0 month lag, but increases to 0.95 , when data prior to 1958 are omitted. The wavelet amplitude diagram (see Abarca del Rio and Cazenave, 1994) of this band-passed LOD and AAM data (Fig. 7a, b), suggests a separation into two bands: a high frequency band (HF) from 1.5 to 2.9 years, and a low-frequency band (LF) from 3 to 5 years. Therefore, to study them naturally, we have filtered both AAM and LOD series into these two spectral bands which we call the quasi-biennial $(\mathrm{QB})$ band and the triennial-quadrennial (TQ) bands, respectively. In what follows, both bands are studied separately.

\subsection{The quasi-biennial oscillation (qbo)}

4.1.1 Correlations. The QBO in LOD and $N C E P_{\mathrm{W}}^{10}$ are compared over 1949 to 1998 in Fig. 8. Both signals agree particularly well; the contemporary correlation is 0.89 (see Table 1). However, when data prior to 1956 is omitted, the correlation increases to 0.94 . With the purpose of investigating different properties of the quasi-biennial oscillations within the atmosphere (Trenberth, 1980), we computed AAM separately over the troposphere and stratosphere. The AAM computed up to $100 \mathrm{hPa}$, hereafter $T A A M$, represents the main variability over the troposphere, while the main variability over the stratosphere (hereafter $S A A M$ ) is given by the difference between the $N C E P_{\mathrm{W}}^{10}$ and the TAAM series. Then the series underwent band pass filtering between 1.5 to 2.9 years to extract the quasi-biennial variability. The QBO in TAAM and SAAM series; T-QBO and S-QBO respectively, compared in Fig. 9, disagrees in amplitude and contains a variable phase shift. It can

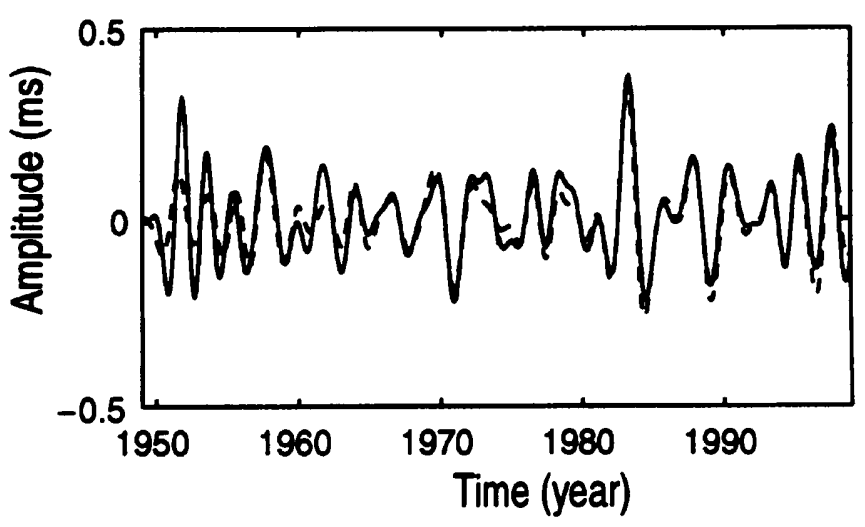

Fig. 6. Interannual variations (between 1.5 and 5 years) of the LOD (solid) and AAM (i.e. $N C E P_{\mathrm{W}}^{10}$ ) (dashed) time series 
a

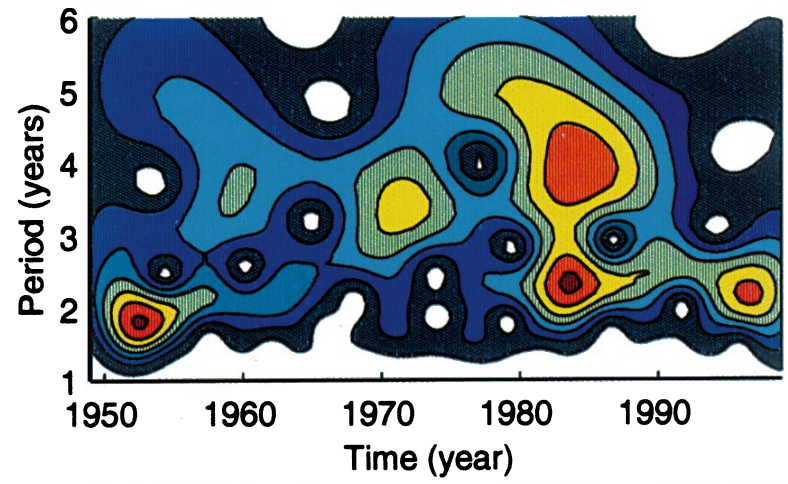

b

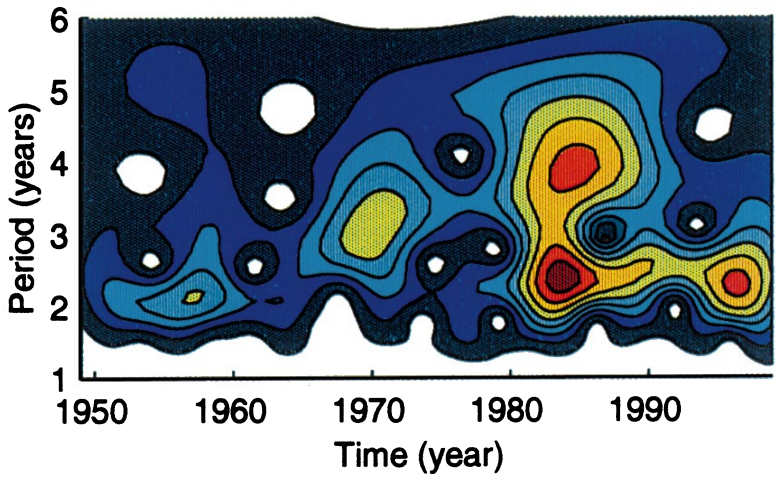

Fig. 7a, b. Amplitude diagram of the wavelet transform of a LOD, b AAM (i.e. $N C E P_{\mathrm{W}}^{10}$ ). Contours at $0.01 \mathrm{~ms}$ intervals

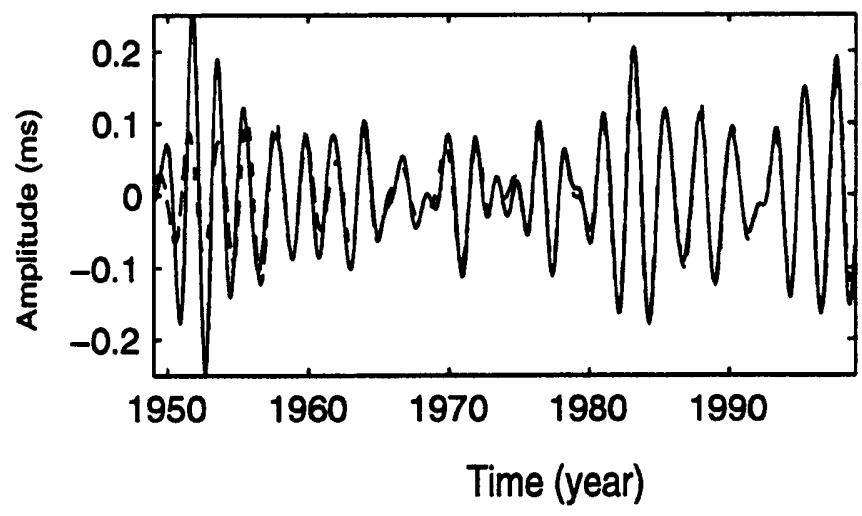

Fig. 8. Interannual variations at the quasi-biennial band (between 1.5 and 2.9 years) of the LOD (solid) and AAM (i.e. $N C E P_{\mathrm{W}}^{10}$ ) (dashed) time series

be noted that the amplitude variability of the $\mathrm{QBO}$ in the $N C E P_{\mathrm{W}}^{10}$ signal and hence in LOD (Fig. 8), is highly dependent on this phase shift; it reaches maxima when

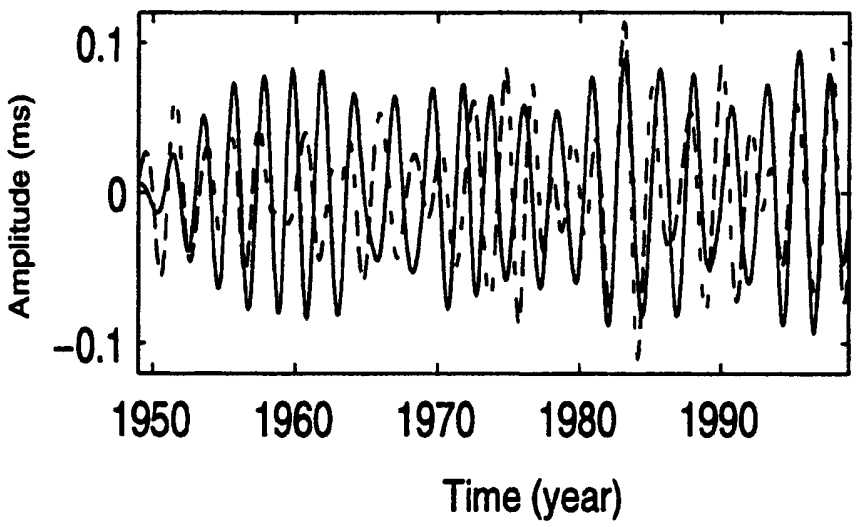

Fig. 9. Interannual variations at the quasi-biennial band (between 1.5 and 2.9 years) of the SAAM (solid) and TAAM (dashed) time series

the tropospheric (T-QBO) and stratospheric (S-QBO) signals are in phase agreement, and minima when they are in phase opposition. The additive feature happens three times during the last 50 years, i.e. 1950-57, 19821983 and 1995-1998. Note that over the last 30 years (1970-1998), this feature took place with periods roughly at 13 year intervals, during large ENSO events. Out of phase (subtractive) relationships took place during years 1960-to-1980, which led to lower amplitude at these time scales in AAM and LOD (in Fig. 7a, b).

To discern particularities in the S-QBO and the T-QBO signals, we extract their amplitude variability (see Torrence and Combo, 1998) (Fig. 10a), which appears to be unrelated. On average, the amplitude of the S-QBO, is almost twice as large as that of the T-QBO, with the exception of particular years, i.e. 1975-76, 1982-83, 1989-90 and 1997-98. In addition the S-QBO presents a pronounced decadal variability, whereas in the T-QBO the dominant modulation is at higher frequencies (5 to 10 years). It is possible, however, that a lower frequency, such as a decadal time scale, participates at the modulation of $\mathrm{T}-\mathrm{QBO}$, but does not appear as a dominant oscillation.

A power spectrum analysis applied to both series (not shown), further confirms differences between QB signals in the stratosphere and troposphere. It reveals that S-QBO contains a strong peak at 2.37 years, whereas that on T-QBO presents bimodal periodicities of roughly 2.1 years and 1.8 years. However, because neither series present equal, or constant periodicities, we also add the extracted periodicities (Fig. 10b) of the dominant amplitude oscillation in both diagrams. This
Table 1. Estimate of correlation coefficients. First column within each band-pass band (in years) gives information on the best correlation found, while the second gives the lag (in months) obtained for that correlation; positive for the first series leading, negative for being lead

\begin{tabular}{|c|c|c|c|c|c|c|c|c|}
\hline \multirow{2}{*}{$\frac{\text { Data//band }}{\text { LOD and } N C E P_{\mathrm{W}}^{10}}$} & \multicolumn{2}{|l|}{$1.5-7.5$} & \multicolumn{2}{|c|}{$1.5-5$ years } & \multicolumn{2}{|c|}{$1.5-2.9$ years } & \multicolumn{2}{|c|}{$3-5$ years } \\
\hline & 0.704 & 0 & 0.896 & 0 & 0.893 & 0 & 0.892 & 0 \\
\hline LOD and TAAM & 0.605 & -0.5 & 0.728 & -0.5 & 0.64 & -0.5 & 0.876 & 0 \\
\hline LOD and $S A A M$ & & & 0.677 & 0 & 0.74 & 0 & -0.64 & +10 \\
\hline$S A A M$ and $T A A M$ & & & & & 0.36 & +26 & & \\
\hline MSOI and LOD & 0.55 & +1 & 0.643 & +1 & 0.582 & +2 & 0.82 & -1.5 \\
\hline MSOI and $N C E P_{\mathrm{W}}^{10}$ & 0.638 & +1 & 0.65 & +1 & 0.555 & +2 & 0.859 & -1.5 \\
\hline MSOI and TAAM & 0.742 & +0.5 & 0.789 & +1 & 0.761 & +0.5 & 0.848 & -1.5 \\
\hline MSOI and $S A A M$ & 0.34 & +460 & 0.406 & +124 & 0.591 & +123 & -0.657 & +20 \\
\hline
\end{tabular}



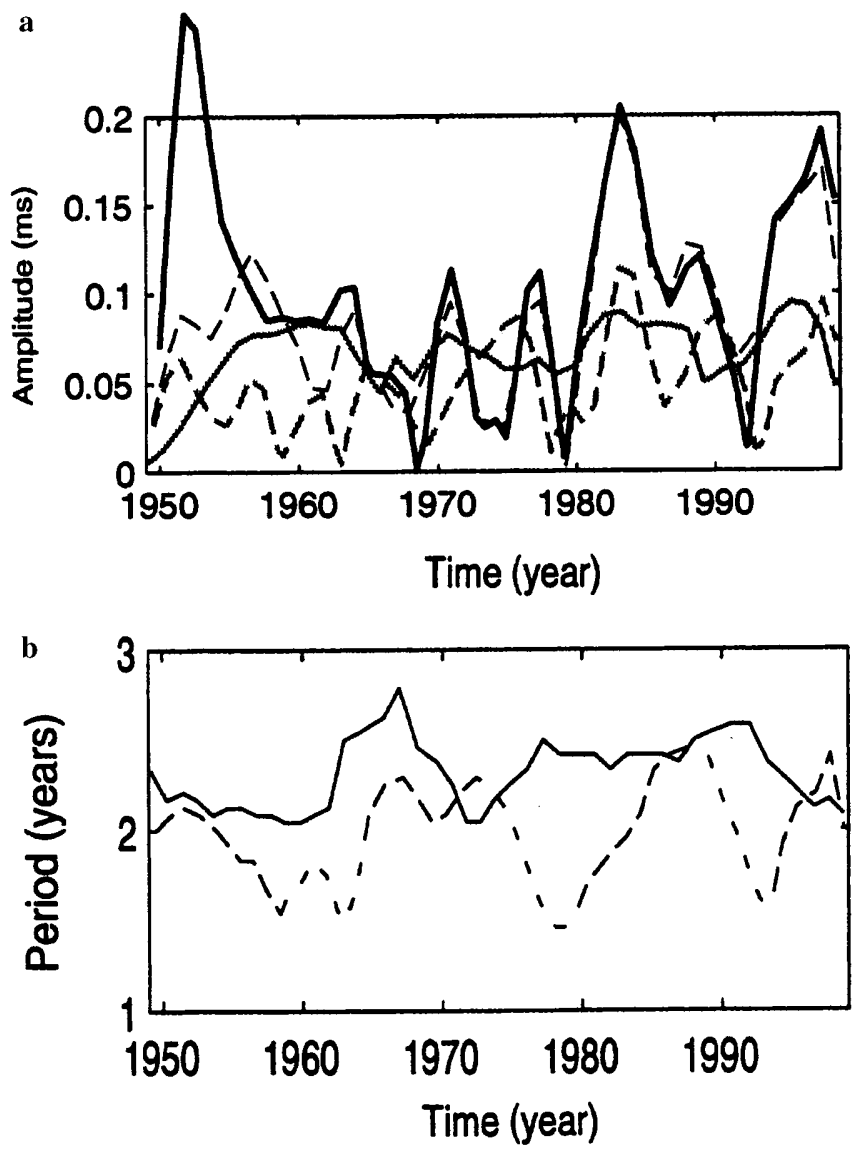

Fig. 10. a Amplitude variability of the quasi-biennial signal in the LOD (bold solid line), AAM (i.e. $N C E P_{\mathrm{W}}^{10}$ ) (dashed line), S-QBO (solid line), T-QBO (dashed bold line) time series. b Period variability of the quasi-biennial signal in the S-QBO (solid), T-QBO (dashed) time series

figure confirms that although sometimes in phase, quasibiennial periodicities in TAAM and SAAM series are neither constant nor equal and vary independently. Here, the T-QBO contains the largest variance. It appears to be modulated by a period of roughly $14-15$ years, with maxima of 2.5 years and minimum of 1.5 years. In addition, it also suggests that the variability in the T-QBO is more complex than that of the S-QBO. On average, compared to that of the T-QBO, the period of the S-QBO is more regular. Before 1972, the period of the S-QBO is as long as 2.85 years, centred in 1967, and as little as 2.1 years, in 1959, but it increases almost regularly from 1972 to 1992 (2.25 to 2.45 years respectively). After 1992, the period of the S-QBO tend to decrease, at a rate of 0.09 year/year comparable to years 1967-1972 (0.16 year/year). These deviations from the regular oscillations in the stratospheric QBO coincide with the Naujokat (1986), Xu (1992) and Fraedrich et al. (1993) findings. According with these investigations, the lower values of the periods in 1959 and 1972, are explained respectively by short westerly and easterly regimes, whereas the higher values during 1989-1992 correspond to relatively long westerly regimes. In particular the strong peak in 1967-68 corresponds to both longer than usual westerly and easterly regimes.
For comparative purposes we also extracted the amplitude variability of LOD and AAM, shown in Fig. 10a. This figure shows that the amplitude in AAM does not always equal that in LOD. Until 1962 the main reason may be found to originate within the quality of the LOD and AAM data, while after 1962 it may be due to the following: firstly the atmospheric assimilation model only extends to $10 \mathrm{mb}$, and although accounting for $99 \%$ of the total atmospheric mass, the upper stratosphere may play a role. Secondly, other sources of excitation, such as oceanic variability may have an effect. This figure also demonstrated that the amplitude variability of the QB signal in AAM, does not always equal the sum of the amplitude of both S-QBO and T-QBO, because of phase variability. Thus, although AAM presents larger variance at epochs when both S-QBO and T-QBO coincide in their larger amplitude variability, other significant variances are shown when neither S-QBO or T-QBO is important. This result further indicates that both series shift over time with respect to one another. The difference in frequency between the troposphere and the stratosphere represents a varying beat frequency, during which the overall strength of the QBO oscillates over the whole atmosphere, and hence, also in LOD. Thus, each of the quasibiennial oscillations within the atmosphere (stratospheric and tropospheric), although containing periods similar for each other, may be unrelated by their nature. This is also suggested by the weak correlation and the corresponding lag between both signals ( 0.36 and 22 months respectively). Note however, that this correlation value, is according with Oort and Yienger (1996), above the $95 \%$ confidence limit for this band (0.33).

It is remarkable that the Southern Oscillation (SO), also contains power around the quasi-biennial period (see Trenberth, 1980; Xu and Storch, 1990), likely related to that in the troposphere. Thus, when we compare the T-QBO and the inverted SOI (MSOI), band-pass filtered to retain periods between 1.5 to 2.9 years (hereafter QB-MSOI), we note a remarkable agreement (Fig. 11). Their best correlation (0.76) is obtained while the QB-MSOI series leads T-QBO by

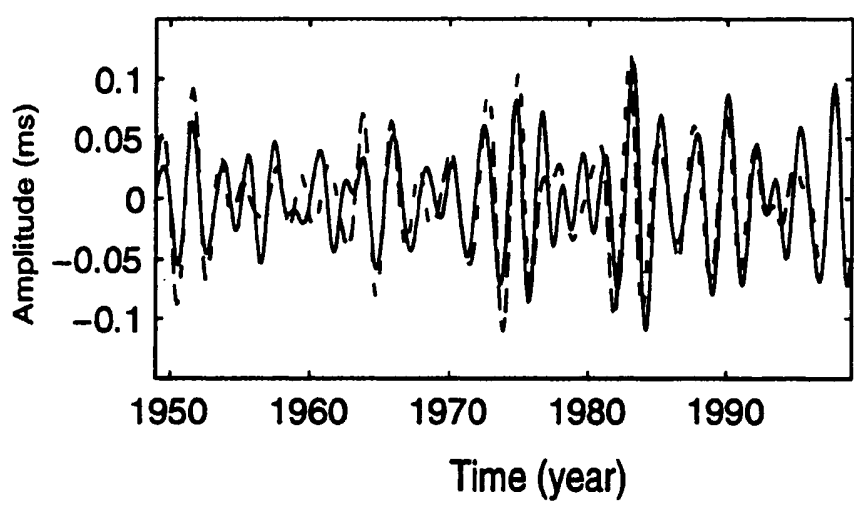

Fig. 11. Interannual variations at the quasi-biennial band (1.5 to 2.9 years) in AAM (solid line), MSOI (dashed) time series. The AAM time series is given in milliseconds, while the inverted SOI (MSOI) time series is given in millibars/10 
0.5-1 month. Therefore that oscillation in the troposphere is connected with the SO variability.

On the other hand, the best correlation found between the S-QBO in the stratosphere and QB-MSOI, investigated within a window of four years, is less than 0.3 , confirming previous findings regarding relationships between stratospheric and tropospheric processes. However extending the correlation-lag to a window of 20 years yields a correlation of 0.59 , but with the QB-MSOI leading the S-QBO by ten years (123 months). Due to the implied lag, it is highly possible that such a correlation has no physical meaning. As a result the correlation found between the QB-MSOI and QBO in LOD or $N C E P_{\mathrm{W}}^{10}$ is less than this found between the QB-MSOI and T-QBO (see Table 1), confirming the negative influence of the S-QBO on relations between the SO and LOD.

4.1.2 Vertical analysis. To diagnose the regional origin of these results, we calculated the relative AAM within each vertical layer for which zonal winds were available (Rosen and Salstein, 1983). In so doing, we computed the global AAM up to each of the layers from $1000 \mathrm{hPa}$ to $10 \mathrm{hPa}$, and constructed the difference between consecutive layers. Care was taken to verify that the sum of the relative AAM through the depth of the atmosphere equals the value of the global AAM (i.e. $\left.N C E P_{\mathrm{W}}^{10}\right)$.

To emphasise the quasi-biennial scale variability, we concentrate on the band between 1.5 and 2.9 years (Fig. 16a). The variability of the stratospheric and tropospheric QB signal appear to have quite different characteristics in this figure. Over most of the time span analysed, waves propagate upward from the surface to upper troposphere $(16 \mathrm{~km})$, and downward from the upper to the lower stratosphere. The correlation between the lower and upper tropospheric layers at the quasi-biennial period is 0.63 at a three month lag, indicating an average propagation speed of three months from the surface layers to the upper troposphere. On the other hand an even stronger lag correlation, of 0.82 , exists between the upper and lower layers of the stratosphere with a wave propagation speed of seven months. According to an multichannel singular spectrum analysis (MSSA; Dettinger et al., 1995b) of these data, with embedding dimensions varying between 36 to 60 months (3 to 5 years), the first and second modes (not shown), contain a downward propagation that explains a considerable percentage $(59 \%)$ of the total variance in AAM, with more than $99 \%$ of this variance located at stratospheric heights. On the other hand, the third and fourth modes (not shown) contain an upward propagation and explains up to $20 \%$ of the total variance, with $88 \%$ of this variance located at tropospheric heights. The sum of these modes represent the entire field, with downward propagation in the stratosphere and upward propagation in the troposphere. However, even by varying the embedding dimensions to critical values ( 8 to 150 months), it was not possible to find any single mode that describes the whole tropospheric-stratospheric structure. This clari- fies the difference between the two waves in AAM. Here it should be mentioned that downward propagation of zonal wind anomalies throughout the depth of the stratosphere, has been noted since 1959, by McCreary (see Wallace, 1973), whereas the upward propagation in the troposphere, to our best knowledge, was first shown by Yasunari (1989). Note however, that episodically downward anomalies extend from the upper to the lower stratosphere during 1953-54, 1960-62, 1977-79, and to a lesser extent 1991-93.

Our study contrasts with that of Yasunari (1989), in that the downward propagation of the westerly (easterly) anomalies in the stratosphere do not simultaneously occur with the upward propagation of westerly (easterly) anomalies at the tropopause through the upper troposphere. Furthermore, the varying beat frequency between quasi-biennial stratospheric and tropospheric processes (Fig. 16a) is clearly suggested during years 1961-1969, 1973-1976, 1984-1994. However, both waves are in phase during 1949-1960, 1969-1972, 1979-1982, and from 1995-1998. Note, too, that since 1960 the phase coincidence occurs only episodically, and for no more than three years, pointing out that the lengthy period 1949-1960 of phase agreement appears quite anomalous.

In the stratosphere, the stronger variability is located about 23-25 km (30-20 hPa), over years 1962-63, 196971, 1982-83 and 1996-97, consistent with the amplitude variability of the S-QBO signal in Fig. 10a. Over the troposphere, according with the earlier study of interannual variability in AAM of Kang and Lau (1994), the maximum variability in AAM is found in the upper part of the troposphere, 10-16 km over years 1951-53, 1964-65, 1973-1976, 1981-1984 and 1988-1991. However, note, too, that over 1982-1985 and 1996-1998, the contribution of the lower part of the troposphere $(<10 \mathrm{~km})$ is also significant. Thus, over years 1982-84 the variance was important all along the tropospheric and stratospheric heights.

4.1.3 Zonal analysis. Since the atmosphere does not rotate as a rigid body, the angular velocity at different latitudes varies independently, as it does at different depths. To gain some idea of how each latitude within the atmosphere contributes to the total angular momentum variability of the troposphere and stratosphere, we calculated at every $2.5^{\circ}$ from $-90^{\circ} \mathrm{S}$ to $90^{\circ} \mathrm{N}$ and for every month since January 1949 to December 1998, the relative AAM up to $100 \mathrm{hPa}$ and between 100 and $10 \mathrm{hPa}$ (see Eq. 1). These fields then undergo a bandpass filtering at the quasi-biennial band (1.5-to-2.9 years).

The tropospheric quasi-biennial variability (Fig. 17a) displays its well known poleward propagation of zonal waves (Trenberth, 1980; Dickey et al., 1992, 1999; Black et al., 1996). The variability of the poleward waves varies with time, agreeing with the amplitude variability of the T-QBO signal in Fig. 9. Consistent with analyses by Black et al. (1996), some evidence of equatorward propagation, though, is also noticeable over the Northern 
Hemisphere, to roughly as far south as $50^{\circ} \mathrm{N}$. The difference between the zonal evolution of the stratospheric (Fig. 17b) and tropospheric (Fig. 17a) waves is evident; most of stratospheric quasi-biennial variability is confined close to the equator, from $30^{\circ} \mathrm{S}$ to $30^{\circ} \mathrm{N}$, and does not exhibit propagation. In addition, it appears that the equatorial tropospheric and stratospheric variabilities are unrelated in their phase as in their amplitude variability. However, this point will need further analysis.

It should be pointed out that before 1955, in Fig. 17a, consistent with the stratospheric part in Fig. 17b and Fig. 11, the oscillations contain less variability. This is probably associated with the lack of quality, quantity, and geographical distribution of the zonal wind values assimilated in the NCEP/NCAR scheme over the years 1949 to 1955. Therefore the phase and amplitude variability of the S-QBO signal over part of the first decade (roughly up to 1956) of the reanalysis years must be regarded with caution.

On the other hand, Figs. 16a, 17a, b, further suggest that stratospheric and tropospheric variability differ in both their vertical and zonal variability. In addition to the differences seen in both of the amplitude and period variability of the QBO in TAAM and SAAM, these results establish firmly that QBO in tropical latitudes dominating AAM variability at these time scales, are linearly unrelated.

\subsection{The triennial-quadrennial oscillation (tqo)}

4.2.1 Correlations. As shown by the wavelet analysis of interannual times scales variability in LOD (Fig. 7a) and $N C E P_{\mathrm{W}}^{10}$ (Fig. 7b), both series contain common oscillations at 3-to-4 year time scales. When the series are filtered in a lower frequency band, between 3 and 5 years, the LOD and $N C E P_{\mathrm{W}}^{10}$ signal (Fig. 12) are very much in phase, with a contemporary correlation of 0.89 . Comparison of $N C E P_{\mathrm{W}}^{10}$ and $N C E P_{\mathrm{W}}^{100}$ signals (not shown), indicates that the stratosphere contributes little to LOD at these time scales, less than $5 \%$ of the explained variability. We note as well, that the central period of this process varies with time. A wavelet analysis (Fig. 7a) shows that LOD periodicities are

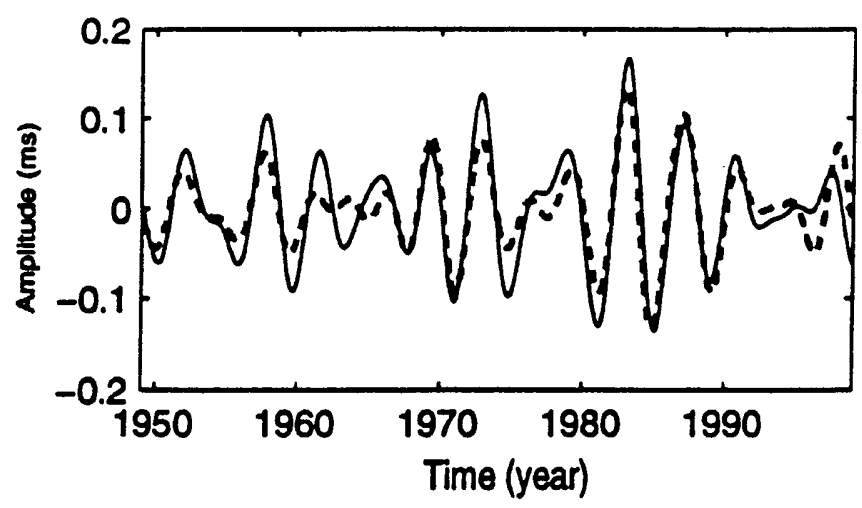

Fig. 12. Interannual variations at the triennial-quadrennial band ( 3 to 5 years) of LOD (solid) AAM (bold dashed) time series

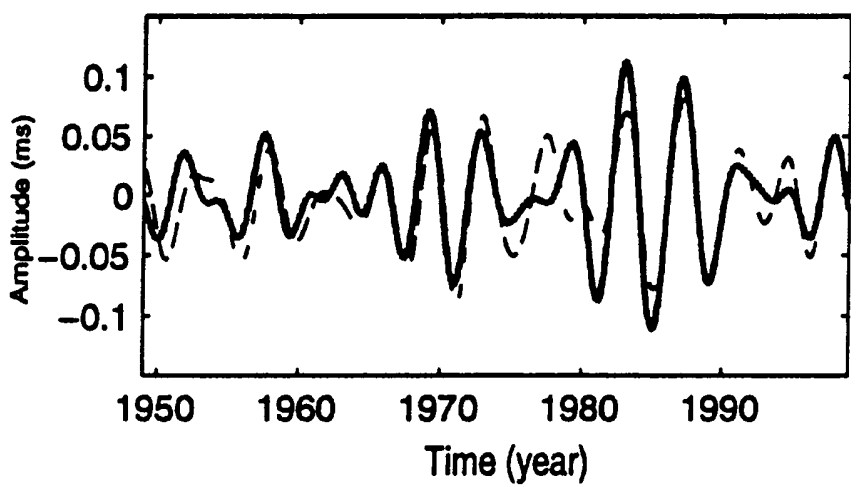

Fig. 13. Interannual variations at the triennial-quadrennial band ( 3 to 5 years) of AAM (i.e. TAAM) (bold) and MSOI/10 (dashed) time series

lower before 1980 than after. This feature is even more evident in the $N C E P_{\mathrm{W}}^{10}$, s wavelet analysis (Fig. $7 \mathrm{~b}$ ). However, between years 1950 to 1965 , LOD has fluctuations which are not mirrored in the AAM data. This may give further evidence that the data assimilated in the NCAR/NCEP reanalyses may be of lower quality during these years. However, it is the case that the LOD data are of significantly lower precision before 1962 (Gross, 1992). Both wavelet diagrams shows also that the years 1980-1990, contain a particularly strong amplitude variability. This result is coincident with the influence of the strong 1982-83 El Niño and other such events. Since 1990, the amplitude of the triennialquadrennial signal decreases in AAM, and nearly disappears in LOD. However, the filtering process might be responsible for some of the reduction in power.

ENSO events, as other tropospheric parameters, have been shown to contain fluctuations at quadrennial times scales (see Torrence and Combo, 1998; Moron et al., 1998). Those of MSOI correlate quite well with AAM and LOD (0.85 and 0.82 respectively), however with MSOI being led by 1.5 months (Fig. 13). The amplitude variability in AAM and LOD appears to be modulated by a lower frequency period of approximately 10-15 years (Fig. 12), coherent with analyses in different tropospheric climatic indices by Torrence and Compo (1998). A comparative analysis of LOD with MSOI back to 1880 (not shown), shows that both TQO signals are in phase agreement as early as around 1920, while disagreeing before. In addition, both signals do not present the same amplitude variability prior to 1920 as well, in line with earlier results of Salstein and Rosen (1986).

4.2.2 Vertical analysis. To gain further insight on which portions of the atmosphere lead to these results, the relative contribution to AAM (Rosen and Salstein, 1983), are here estimated for the TQ band, between 3-to-5 years (Fig. 16b). As for the quasi-biennial signal, the evolution through the depth of the atmosphere can be separated into downward stratospheric and upward tropospheric waves. The correlation between the lower 
(1000-to-925 hPa) and upper tropospheric layers (150to- $100 \mathrm{hPa}$ ) is 0.78 , with the lower layers leading by three months, indicating an average propagation speed of three months from the surface layers to the upper troposphere. Over the stratosphere, the correlation between the upper and lower layers is 0.56 , with an average wave propagation speed of five months. This correlation value, is according with Oort and Yienger (1996), above the $95 \%$ confidence limit for this band (0.5).

Compared to the QB time scales, the variability in the TQ band is inverted, with the greater amplitude variability found over the troposphere, and little over the stratosphere. Tropospheric variability can be divided into three periods of important activity; 1949-1960, 1965-1974 and 1980-1990, with each period lasting about ten years, with the strongest being 1980-1990. In addition, the years 1997-98 seem to correspond to the commencement of a new period of activity. Over the 50 years, the vertical location of the maxima varies with time. During 1949-1960 and 1965-1974 the most important variability is located over the upper troposphere (10 to $16 \mathrm{~km})$, consistent with results by Kang and Lau (1994). However, during 1980-1990, maxima are found in both the upper and lower part of the troposphere, with the most important variability in 1983-1985, in the lower troposphere $( \pm 8 \mathrm{~km})$. This feature seems to be repeating again in years 1997-98. Intervals of quiet activity are also present; 1960-1965, 1974-1979 and 1990-1996. During these quiet intervals, in particular during 1974-1977 and 1990-1994, downward propagating waves from the upper stratosphere down to the lower troposphere are suggested.

4.2.3 Zonal analysis. We investigate as well the meridional variability of the 3-to-5 year filtered TQ band, highlighted in Fig. 17c. Here the well-known poleward propagation of quadrennial-waves (Dickey et al., 1992; Black et al., 1996) is evident, but a lack of variability exists before 1958. Moreover, we note the presence of equatorward waves originating within polar latitudes, especially in the Southern Hemisphere over 1990-1995. This feature can also be seen over years 1960-1985, where westerly and easterly equatorward tongues extend up to $40-50^{\circ} \mathrm{S}$. Here it should be noted that during the quiet periods, 1960-1965, 1975-1980 and from 19901995, the equatorward mode extends to the tropical latitudes, where both equatorward and poleward signals may interact. We note too, that before 1960 the equatorward variability is less prominent.

The explained variance of the equatorward and poleward waves is not equivalent. The latter appears to dominate almost the whole 50 years. To investigate this point, the MSSA (Dettinger et al., 1995b) technique was applied to the band-pass filtered field in Fig. 17c. The robustness of the results has been validated here by the fact that this technique was applied with embedding dimensions (window lengths) varying from 8 to 120 months (less than one fourth the length of the data). All the results are self-consistent, with dominant poleward modes accompanied by the presence of equatorward modes, and are also reconfirmed by a simple extended empirical orthogonal function (EEOF). From a MSSA with an embedding dimension of 60 months (five years) the first four modes explain $74 \%$ of the total variance. The first two reconstructed components (summed up in Fig. 17d), contain the polarward waves that explain $56 \%$ of the total variance. The third and fourth reconstructed components (summed up in Fig. 17e), contain the equatorward waves that explain $18 \%$ of the total variance. The poleward waves of the field in Fig. 17c, are well reproduced by the sum of the first two modes (Fig. 17d). Both figures (Fig. 17c, d) suggest that the poleward waves, present a decadal modulation of about 13-15 years, over years 1960-1998. But the lack of variability before 1960, prevent us for drawing any conclusion over the entire time span analysed (19491998). The equatorward mode (Fig. 17e), as derived from the MSSA, contains three epochs of intense activity; 1955-1965, 1975-1981, 1990-1998, with the most important variance seen over the years 1979-1981. Since the data before year 1960, suffers from a lack of quality, it is difficult to determine precisely the amplitude modulation of these equatorward waves. These waves take typically on average 3 to 4 years to propagate from the southern polar latitudes $\left(70-80^{\circ} \mathrm{S}\right)$ to the tropics, whereas in the Northern Hemisphere the propagation starts at $50^{\circ} \mathrm{N}$. As for the poleward waves, variability in the Northern Hemisphere, north of $50^{\circ} \mathrm{N}$ is different.

The origin of the equatorward waves is difficult to assess without a more complete analysis. However, let us note that equatorward modes have also been shown in the case of the much more rapid subseasonal MaddenJulian oscillations in AAM by Dickey et al. (1991). The origin of both could be related to mobile polar highs (MPH) (Leroux, 1993), which may originate in the downward air motion in the polar latitudes, before moving equatorward. However, since the tropical poleward waves are the dominant variety, this implies that the MPH are only a minor component of the total variability in the global climate system, and not a key factor in climate as proposed by Leroux (1993).

In Fig. 14 the TQO in the troposphere, i.e. in the $N C E P_{\mathrm{W}}^{100}$ signal, the global AAM in the troposphere, due to the poleward waves (hereafter PW), and the global AAM in the troposphere due to the equatorward waves (EW) are presented together. The tropospheric TQO signal in Fig. 14 is correlated at a 0.97 level with the sum of both the PW and EW waves contribution (see Table 2). However, the correlation with the poleward signal alone reaches only 0.87 . Therefore, both modes are needed for explaining the TQO variability in the $N C E P_{\mathrm{W}}^{100}$ signal. For example, even though the $\mathrm{PW}$ signal explains $65 \%$ of the variance, the EW signal, explaining on average $16 \%$ of the TQ variance, has a significant contribution over 1982-83 and 1997-98. Thus, during 1982-83, the contribution of the EW is $50 \%$ that of the PW signal. Instead, over 1997-98 the EW signal explains most of the TQ signal. We note as well that during these two epochs (1982-83 and 1997- 


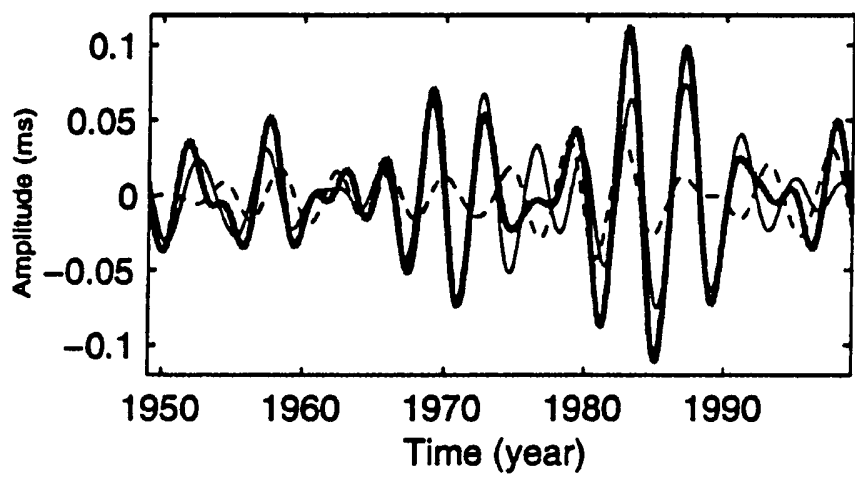

Fig. 14. Interannual variations at the triennial-quadrennial band ( 3 to 5 years) of AAM (i.e. TAAM) (bold), polarward mode (solid), equatorward mode (dashed)

Table 2. As for Table 1. Here for the TQO band only

\begin{tabular}{llc}
\hline Data//band & $3-5$ & \\
\hline MSOI and (PW + EW) & 0.855 & -2 \\
MSOI and PW & 0.839 & -2.5 \\
MSOI and EW & 0.571 & +90 \\
TAAM and (PW + EW) & 0.97 & 0 \\
TAAM and PW & 0.87 & 0 \\
\hline
\end{tabular}

98), the variability of the EW contribution to the global AAM is equivalent. Therefore, the lack of variability at the TQ band during 1997-98 may be due to the lack of variability in the PW waves. However at present, it appears doubtful to assign any confidence level on the equatorward or poleward contribution for the last two years.

Since ENSO is an equatorial phenomena, the poleward waves may be related to the SO as proposed by Dickey et al. (1992) and Black et al. (1996). The correlation of the TQ in MSOI (TQ-MSOI) with the PW signal is 0.84 at a 2.5 month lag (PW leading) (see Table 2). Instead, the correlation found between the TQ-MSOI and the EW signal is considerably less: within a window of three years, the correlation does not attain 0.3 . We note that AAM and MSOI peak at different epochs (Fig. 13); the most important amplitude takes place during 1986-87 in MSOI and during 1982-83 in AAM. We note as well, in comparing Figs. 13 and 14, that the amplitude of the 1972-73 and 1982-83 peaks are comparable in the TQ-MSOI and PW signals, but are larger for $1982-83$ in the TQ signal in $N C E P_{\mathrm{W}}^{100}$. Also, as already noted, the most important amplitude in the MSOI signal is found in 1986-87, agreeing with the PW signal. Therefore, the larger amplitude variability of the 1982-83 peak in $N C E P_{\mathrm{W}}^{100}$ signal happens to be related to the sum of both poleward and equatorward contributions.

The same MSSA technique, applied at the vertical contribution (Fig. 16b) did not succeed in separating the poleward and equatorward components. This result is probably due to the fact that both poleward and equatorward modes may generate upward propagating waves through the atmosphere. However, although the
EW signal explains on average less than $20 \%$ of the total signal, which even though it is small, is suggestive of some importance. A more complete analysis devoted solely to the equatorward waves, is currently in preparation and will be reported elsewhere.

\section{Interaction between cycles and ENSO events}

\subsection{Additive processes within the atmosphere}

Dickey et al. (1992), following Barnett (1991) and Yasunari (1985), give evidence of interactions between a quadrennial cycle and the quasi-biennial cycle in the tropics which is related to the presence of strong El Niño events. The correlation between the interannual signal (1.5-to-5 years) in TAAM and MSOI is about 0.79 , at a one month lag with MSOI leading (see Table 1). The correlation between MSOI and TAAM in their QB and TQ bands is 0.76 and 0.86 , respectively, being lead and lagged by MSOI, respectively (see Table 1). Therefore, as shown, the strong correlation at interannual time scales between MSOI and TAAM, is explained by the influence of ENSO on triennial-quadrennial and quasibiennial cycles in the troposphere. The alignment of their maxima is typically related to periods of strong ENSO activity (Dickey et al., 1992). We have now analysed these questions with the 50-year long reanalysis set.

The maxima of the QB and TQ series over the troposphere, as their phase concordance is shown in the filtered series (Fig. 15). Thirteen large-scale ENSO events, including the 1997-98 event, occur (see Quinn, 1992), over the last 50 years. They are indicated on Fig. 15 by a letter relating to their strength. Although the phase concordance happens six times (1951-52, 1957-58, 1965-66, 1972-73, 1982-83, 1997-98), all during ENSO episodes, the strongest (1972-73, 198283 and 1997-98) are characterised by QB and TQ oscillations showing amplitudes higher than $0.05 \mathrm{~ms}$. This result illustrates the relationship between strong ENSO events and the amplitude variability of these oscillations. Most of the reported weak or moderate ENSO occurrences are characterised by weak QB or TQ oscillations (1953-54, 1974-75, 1975-76), both weak (1963-64), or phase opposition (1968-69). During the weak 1979-1980 and moderate 1986-87 event, both oscillations are phase lagged, whereas the 1990-95 long ENSO (Trenberth and Hoar, 1996) took place while the amplitude of the quadrennial period is very low. As a confirmation the 1997-98 event also shows a phase agreement between the QBO and the TQO. Note that the amplitude of the QB cycle during 1982-83 and 199798 events are comparable ( 0.12 and $0.1 \mathrm{~ms}$ respectively). However, the amplitude of the TQO during the 1982-83 event is $50 \%$ higher than that of the 1997-98 event ( 0.12 and $0.05 \mathrm{~ms}$ respectively), explaining in large part, the lack of amplitude of this last very strong event when compared to the former. This fact agrees with the $\mathrm{Xu}$ and Storch (1992) study on the basic importance of the QB variability in ENSO events. Thus, ENSO (warm) 


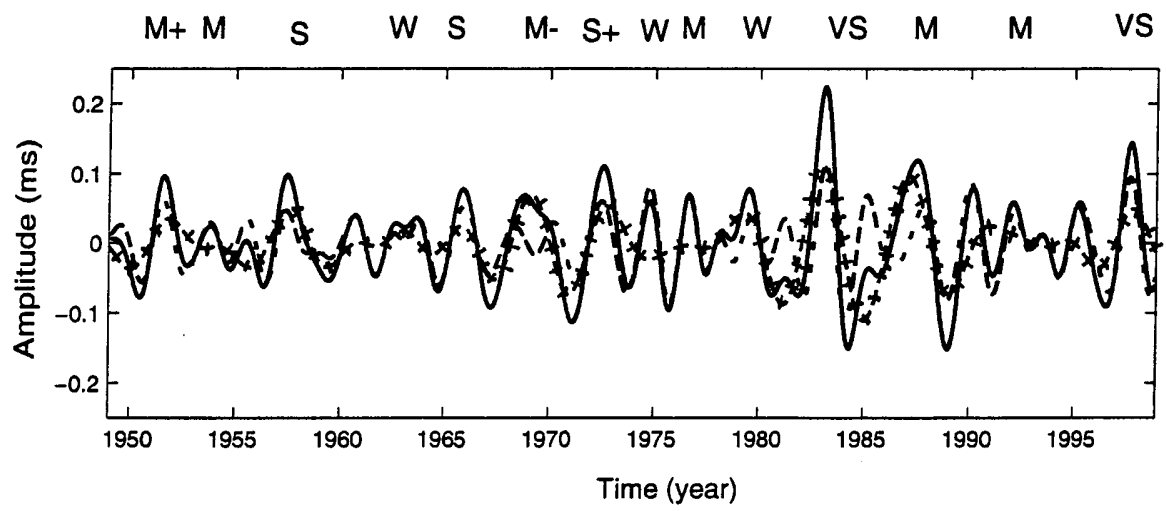

Fig. 15. Interannual variations in AAM (i.e. $T A A M$ ): interannual, 1.5 to 5 years bold line; quasi-biennial band, 1.5 to 2.9 years dashed line; triennial-quadrennial band (3 to 5 years) dashed line plus signs episodes in AAM, tend to coincide with the major peaks in the biennially filtered times series, but all biennial peaks do not correspond to warm episodes (e.g. years 1960, 1981 and 1985). Over these 50 years, phase concordance and strong amplitude of both the quasibiennial and triennial-quadrennial oscillations appears to be a necessary condition of a strong ENSO event in AAM.

The relative AAM variability over the atmospheric layers for all interannual times scales (1.5 to 5 years), shown in Fig. 16c, can further highlight additive processes in the atmosphere. This figure is better understood as the sum of the fields represented in Fig. 16a and Fig. 16b. As already noted, both QBO (tropospheric and stratospheric) signals coincide over 1982-83 with the result of making the 1982-83 peak important in $N C E P_{\mathrm{W}}^{10}$, mirroring the result in the LOD series (Fig. 8). In addition to this point, the additive processes occurring within the troposphere, between the TQO and QBO, as phase coincidence of both phenomena with the S-QBO is clearly evident in Fig. 16c. Although the relationship between the $\mathrm{SO}$ and AAM over the troposphere explains all ENSO events in the total AAM, this figure clearly shows that years 1958-59, 1971-73, 1982-83 and 1997-98 present phase variability through the whole atmosphere, including the stratosphere. When these additive processes occur, they conclude in making the AAM signal particularly strong, therefore increasing the ENSO event signal in AAM.

\subsection{Additive processes in $L O D$}

Although AAM represent the main part of the interannual variability in LOD, interaction with the SYO can give a further clue to El Niño years in LOD. Note that since the SYO is not related to the atmosphere, it is not affected by El Niño. Thus, the correlation between LOD and AAM, band pass filtered at 1.5-to-5 years, is 0.89, while it is only 0.72 when both signals are band pass filtered at 1.5-to-7.5 years. Note too, that during the 1982-83 ENSO event, the six year period in LOD, happens to be in phase with all atmospheric modes (S-QBO, T-QBO and TQO). It increases the El Niño signal in LOD artificially. Such an exact phase concurrence of the SYO with all atmospheric modes has not been repeated during these 50 years. However, during 1958-59 and 1972-73, the maximum of the six year period is slightly lagged with respect to the TQ or QB oscillations. This increases again the amplitude of LOD towards AAM, enhancing artificially the El Niño signal in LOD.

We note however, that the coincidence in phase between some positive peaks in the SYO and some ENSO events, which enhances the visual relation between El Niño events and the interannual variability in LOD, does not enhance the true correlation between both signals. Thus, for the 1.5-7.5 years pass band filtered series, while the correlation between AAM and MSOI is 0.63 , that of LOD with MSOI is only 0.55 , and both have MSOI leading by a month (see Table 1). This reduction provides further evidence that the SYO in LOD is not mirrored in the SO. We note also that the correlation between the MSOI and the TAAM series is higher (0.74) than with the entire AAM, i.e. $N C E P_{\mathrm{W}}^{10}$ (MSOI and $N C E P_{\mathrm{W}}^{10}$ in Table 1). Therefore the influence of the stratospheric QBO and SYO in LOD results in decreasing the correlation with MSOI.

\section{Discussion and conclusion}

On the basis of the complete analysis of the various signals in atmospheric angular momentum and length of day variability over 1949 to 1998, the following conclusions have been reached.

1. LOD variability, investigated at interannual time scales, from 1949 to 1998 , can be partitioned into three spectral lines: a quasi-biennial, a triennial-quadrennial and one at six-seven years, but the AAM only contain power in the first two.

2. Variability in LOD near the six year period, noted before for earlier eras (Vondrak, 1977; Djurovic and Pâquet, 1996), were reconfirmed here. Signals over these lengthier periods are not present in the AAM series and must therefore have a source other than the atmosphere. Notably, too, signals in polar motion, the other Earth motion about the equatorial plane, were also detected at that period (Abarca del Rio and Cazenave, 1994) over 1962-1992, and shown also to be unrelated to the atmosphere over 1980-1992. This result therefore confirms that this period of Earth rotation variability (LOD 
a

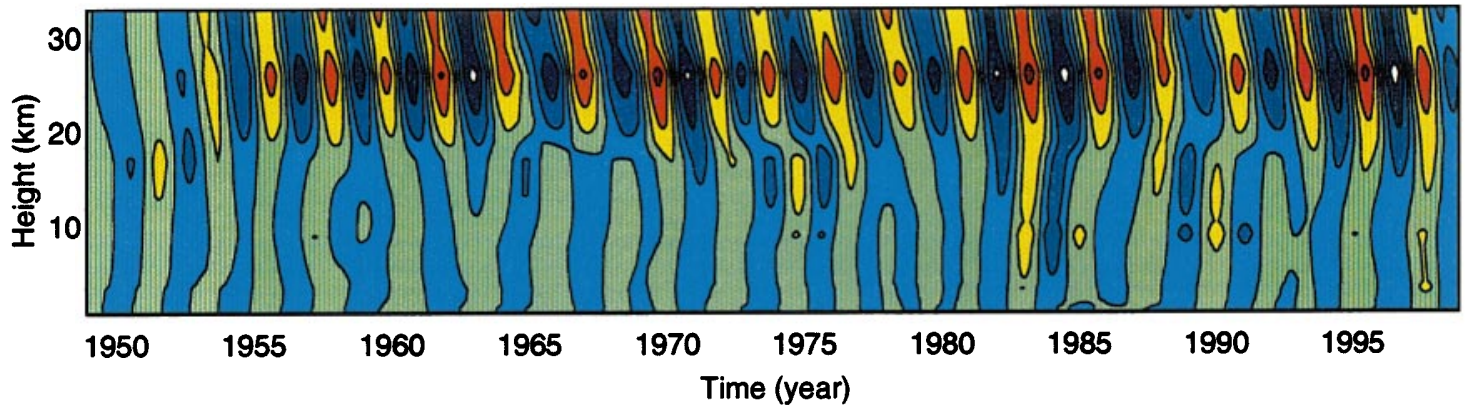

b

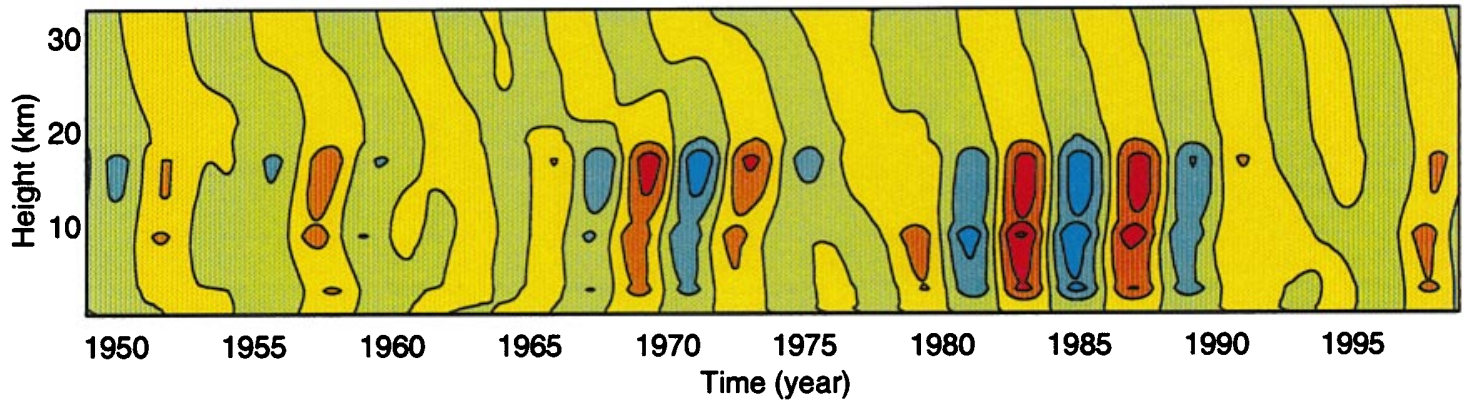

c

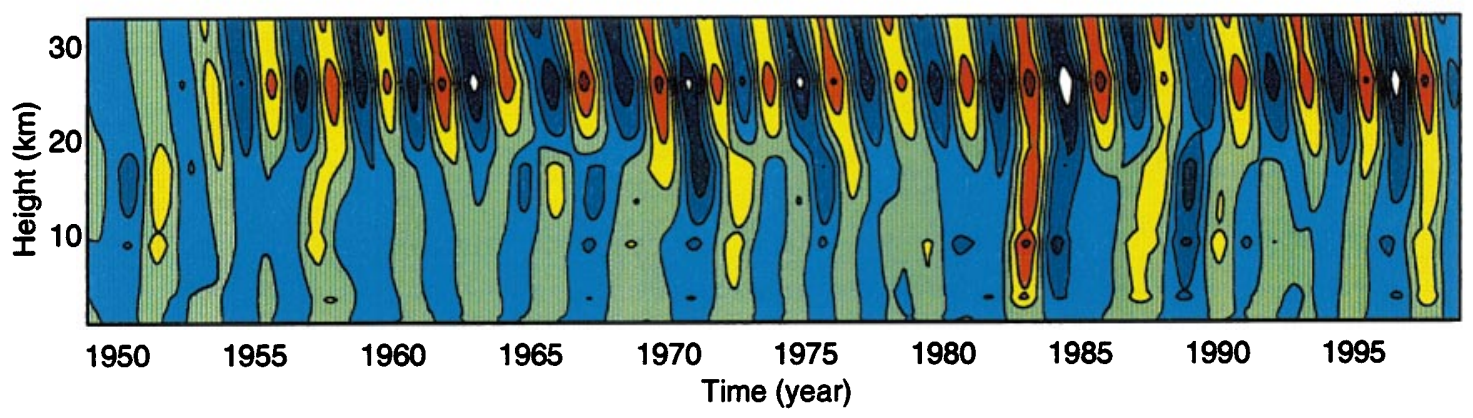

Fig. 16a-c. Relative AAM contribution as a function of atmospheric depth. a Quasi-biennial variability (1.5 to 2.9 years), b triennialquadrennial variability ( 3 to 5 years), $\mathbf{c}$ interannual variability (1.5 to 5 years). The ordinate height is in $\mathrm{km}$. For a and c, positive contributions are coloured from green to dark red and negative

and polar motion) must arise from non-atmospheric processes. Indeed, analysis with a longer LOD data set indicates that a peak at these periods was present over much of the century; it is significant particularly since 1925, when the historic data (Jordi et al., 1994) have lower error characteristics and better resolution. Its variability, with an average amplitude of $0.12 \mathrm{~ms}$, strongly suggest that interactions in this band are related to exchange of momentum at the mantle-core boundary. Therefore, as proposed by Buffett (1996), the mantle and the core may be exchanging momentum at these longer interannual time scales. Other reservoirs, such as oceanic circulation, may participate in the excitation of this oscillation, and their contribution will have to be carefully estimated before a definitive conclusion may be reached. However, based on the low contribution of the oceanic reservoir on seasonal time scales in LOD, less than 5\% (Marcus et al., 1998), and as suggested for other interannual time scales (Abarca del Rio et al., 1999), its contribution at these longer interannual scales may be also negligible. contributions from blue to deep blue, with contour at $0.01 \mathrm{~ms}$ intervals. For $\mathbf{b}$, positive contributions are coloured from orange to red, negative contributions from light green to light blue, at $0.005 \mathrm{~ms}$ intervals

3. In the triennial-quadrennial band, LOD and AAM are closely correlated. They fluctuate between the more rapid part of this range (lower than four years), during the earlier part of the record (1949-75), to a longer oscillation period (higher than four years) in the later part (after 1980). This mode in LOD is excited mainly by the troposphere, and closely connected to the variability in the Southern Oscillation, explaining partly the origin of the links in LOD and the SOI at interannual time scales. We investigated as well the variability at this range over the depth of the atmosphere. The evolution can be separated into downward stratospheric and upward tropospheric waves. Waves propagate from the lower to the upper layers of troposphere in about three months, and from the upper to the lower layers of the stratosphere in about five months. On average the larger variability is located in the upper part of the troposphere, consistent with results by Kang and Lau (1992). It happens, however, that over certain epochs, the main variability originates in the lower troposphere. Analysis in zonal means indicates, that in addition to the 
a

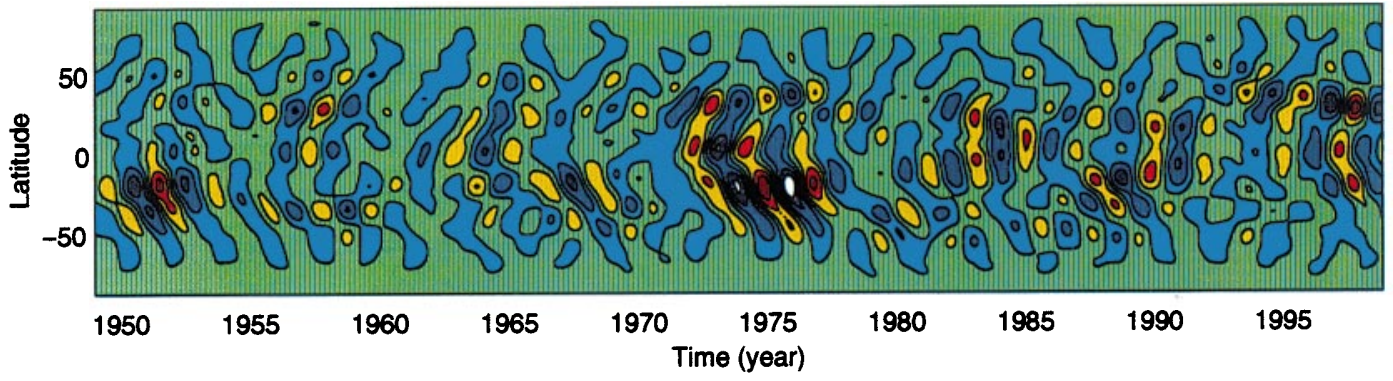

b

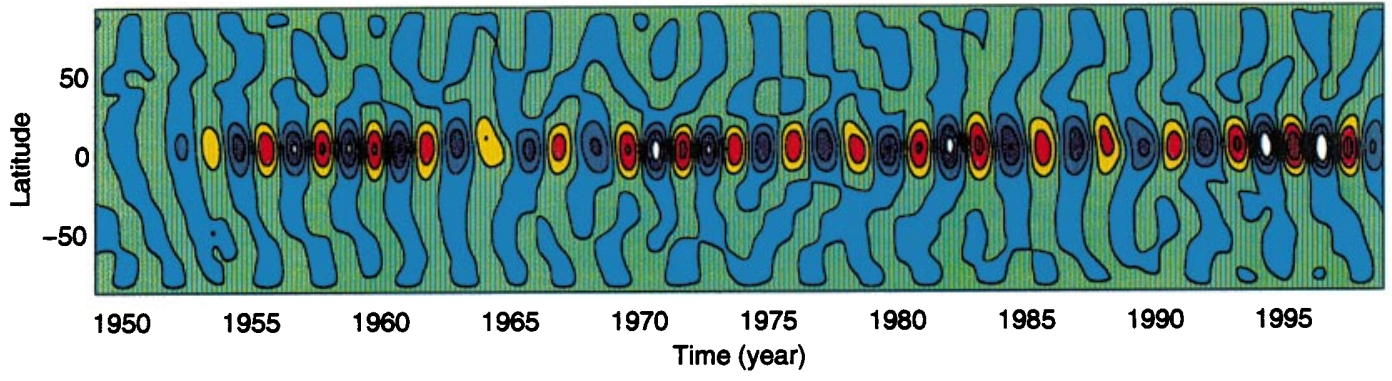

c

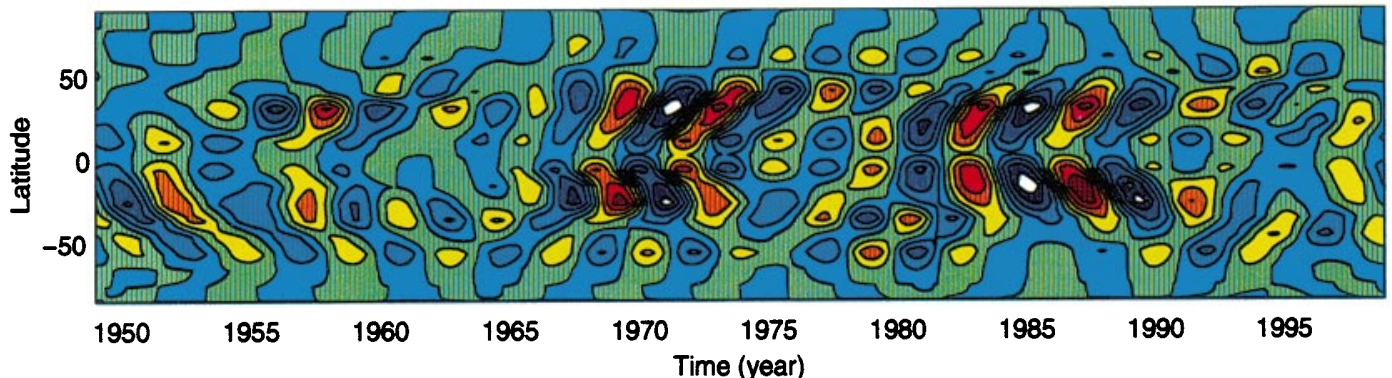

d

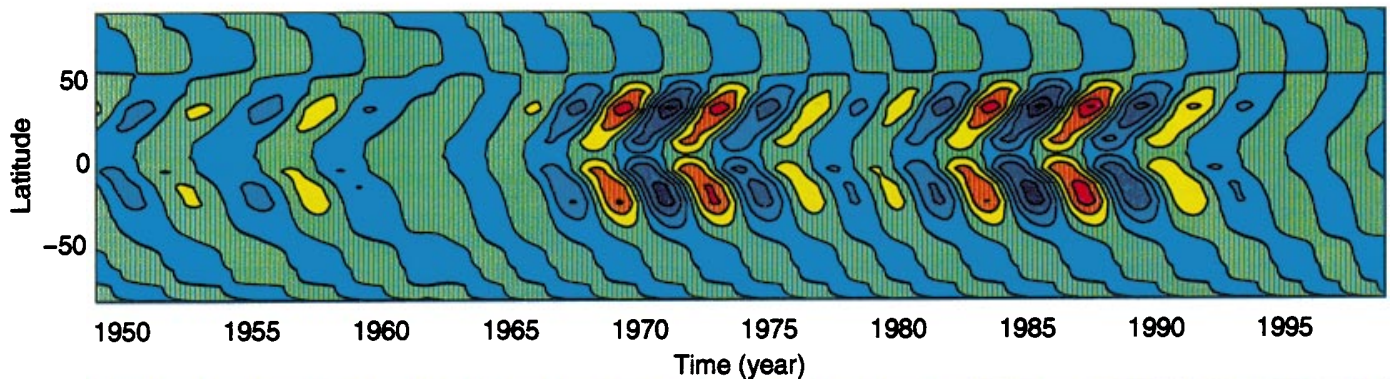

e

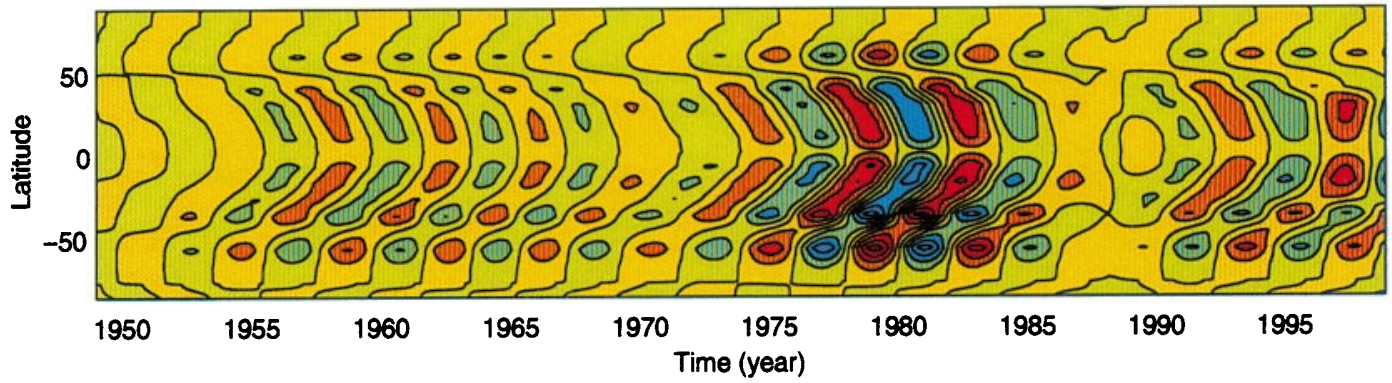

Fig. 17a-e. Relative AAM contribution as a function of latitude. a Quasi-biennial variability ( 1.5 to 2.9 years) over the troposphere, b Quasi-biennial variability (1.5 to 2.9 years) over the stratosphere, c triennial-quadrennial variability (3 to 5 years) over the troposphere. Sum of the reconstructed patterns of $\mathbf{d}$ the first and second components, and e the third and fourth components, of the tropospheric triennial-quadrennial variability presented in c. For $\mathbf{a}$ and $\mathbf{b}$, positive contributions are shown from green to dark red, negative contributions from blue to white, at $0.0025 \mathrm{~ms}$ intervals. For $\mathbf{c}$ and $\mathbf{d}$, positive contributions are from green to dark red, negative contributions from blue to white, at $0.00125 \mathrm{~ms}$ intervals. For e, positive contributions are coloured from orange to red, negative contributions from light green to light blue, at $0.000625 \mathrm{~ms}$ intervals. The ordinate is degrees of latitude 
preceding analysis on this subject, which presented only poleward modes about these frequencies (Dickey et al., 1992, 1999; Black et al., 1996), some equatorward modes are also present. Thus, although the poleward mode explains much of the triennial-quadrennial signal in AAM, the higher amplitude during 1982-83 and towards $1972-73$ peaks, can only be explained by the contribution of the equatorward mode.

4. The quasi-biennial oscillation in LOD is demonstrated to be mainly excited by zonal winds influence in AAM. The main part of the QBO signal in AAM is of stratospheric origin, confirming previous work by Chao (1989). Conversely, the quasi-biennial variability in tropospheric AAM is confirmed here to be linked to that in the Southern Oscillation. Analysis in zonal means indicates that over the stratosphere, AAM variability on this time scale is primarily occurring between $30^{\circ} \mathrm{N}$ to $30^{\circ} \mathrm{S}$, We investigated as well the variability at this range over the depth of the atmosphere. Waves propagate from the lower to the upper layers of troposphere in about three months, and from the upper to the lower layers of the stratosphere in about seven months. Our results indicate that both stratospheric and tropospheric QB oscillations in AAM are unrelated as to their phase variability and shift through time towards each other. As the result of such a process in the evolution of the quasi-biennial evolution in LOD, an extremely high amplitude in AAM occurred during the particularly strong 1982-83 and 1997-98 El Niño year when the two QBO signals were in phase.

Because of the demonstrated differences between stratospheric and tropospheric QB processes presented in AAM, whether the two QBOs are interconnected, is also an interesting question. Whereas there may be an influence of the stratospheric quasi-biennial oscillation on the troposphere or the inverse, we did not diagnose the interactions in detail here. However, as noted, the stratospheric signal has some downward propagation into the troposphere, and may influence the climate variability, although this influence is largely episodic. Indeed, since this study did not investigate local relationships between both, a local or time dependent stratosphere-troposphere connection cannot be rejected. In particular, a recent study by Geller et al. (1997) suggests that the relation between the stratosphere and the troposphere should not be interpreted as linear. Nevertheless, the further analyses performed here, allows us to indicate that globally the QBO in AAM over the troposphere and stratosphere are linearly unrelated.

5. We extend in time previous works (Dickey et al., 1992, 1999; Black et al., 1996) on the interaction between different oscillations in AAM. Over 19491998, a coincidence of two maxima in the tropospheric variability in AAM is not needed to obtain a maximum in AAM; however, when such a coincidence does occur, especially with strong amplitude, it yields an important signal in the tropospheric part of the AAM signal. Also, during the strong 1982-83 and 1996-97 ENSO event, the stratospheric QBO and both tropospheric oscillations were unusually in phase, demonstrating that the stratosphere may influence these particular events. Nevertheless, because of the small number of strong events (four) over the last 50 years, further analysis will be needed over a longer period to establish the necessity of the phase concurrence hypothesis. We note also that even though the 1997-1998 event was considered as least as strong as that of 1982-83, when looked at as an anomaly from the mean climatological conditions (Salstein, 1999), it has not been mirrored fully in the interannual signals in AAM or LOD. This feature is mostly due to the TQ signal at that epoch which is lower by a half when compared to that of 1982-83. Alternately, high frequency variability probably associated with the Madden-Julian oscillation, may explain the important anomaly to mean climatological conditions and other lower frequency events may also have played important roles in the 1997-98 ENSO event.

\section{Summary}

LOD variability, investigated at interannual time scales, from 1949 to 1998, can be partitioned into three bands: a quasi-biennial, a triennial-quadrennial and one at six to seven years, but the AAM only contain power in the first two. The AAM fluctuations at the QB band, can be separated into downward stratospheric and upward tropospheric oscillations with different phase and amplitude variability, although both coincide particularly over certain epochs, i.e. 1982-83 and 1997-98. In the TQ band, this signal originates mainly within an upward propagating mode in the troposphere. At these ranges, although the main signal is explained by an equatorial polarward mode, a polar equatorward mode is found here to explain, on average, more than $15 \%$ of the variability at these time scales. Finally, a six year period in LOD is found to be absent in atmospheric excitation, and is probably associated with mantle-core exchanges of angular momentum.

Acknowledgements. We are indebted to Eric Breitenberger of the University of Alaska for providing SSA and MSSA routines in a Matlab environment. Correspondence with Mike Dettinger of Scripps Institution of Oceanography helped in our use of these techniques. Advice on the wavelet tool on the matlab environment was kindly provided by Chris Torrence and Julian Compo from University of Columbia. The Southern Oscillation data (SOI) was obtained thanks to Todd Mitchell from the University of Washington. The zonal wind field from the atmospheric reanalyses of NCEP/NCAR were obtained from NCAR thanks to Wesley Ebisuzaki. Programs used to compute AAM were obtained thanks to Peter Nelson of AER, who also calculated the Fourier spectra and Fourier band-pass filtered series here. Richard D. Rosen of AER and two anonymous referees made useful comments on our text. This work was done while the first author was performing a postdoctoral at LEGOS, under financial support from LPCM, Paris. Support for D.A. Salstein is through Grant NAG5-6309 of the U.S. National Aeronautics and Space Administration (NASA).

Topical Editor F. Vial thanks two referees for their help in evaluating this paper. 


\section{References}

Abarca del Rio, R., La rotation de la Terre: Etude du cycle annuel et de la variabilité basse frecquence. Variations climatiques de la rotation de la Terre., PhD Thesis, Université Paul Sabatier, 1997.

Abarca del Rio, R., and A. Cazenave, Interannual variations in the earth's polar motion for 1963-1991: comparison with atmospheric angular momentum over 1980-1991, Geophys. Res. Lett., 21, 2361-2364, 1994.

Abarca del Rio, R., B. Dewitte, Y. du Penhoat, and D. Gambis, Tropical pacific ocean long waves contributions to length of day during ENSO 1980-1997, in IERS Technical note 26: the impact of El Nino and other low-frequency signals on Earth rotation and global Earth system parameters, Eds. D. Salstein, B. Kolaczek, and D. Gambis, Observatoire de Paris, Paris, 45-49, 1999.

Angell, J. K., On the variation in period and amplitude of the quasi-biennial oscillation in the equatorial stratosphere 195185, Mon. Weather Rev., 114, 2272-2278, 1986.

Angell, J. K., Evidence of a relation between El Niño and QBO, and for an El Niño in 1991-1992, Geophys. Res. Lett., 19, 285288, 1992.

Baldwin, M. P., and D. O'Sullivan, Stratospheric effects of ENSOrelated tropospheric circulation anomalies, J. Clim., 8, 649-667, 1995.

Barnes, R. T. H., R. Hide, A.A. White, and C. A. Wilson, Atmospheric angular momentum fluctuations, length of day changes and polar motion, Proc. R. Soc. Lonon, 387, 31-73, 1983.

Barnett, T. P., A solar-ocean relation: fact or fiction?, Geophys. Res. Lett., 16, 803-806, 1989.

Barnett, T. P., The interaction of multiple time scales in the tropical climate system, J. Clim., 4, 269-285, 1991.

Barnston, A. G., R. E. Livezey, and M. S. Halpert, Modulation of Southern Oscillation-Northern Hemisphere mid-winter climate relationships by the QBO, J. Clim., 4, 203-217, 1991.

Bell, M. J., and S. Nitsas, An intercomparison of four sets of atmospheric angular momentum data and a discussion of the dynamics of the equatorial components, Meteorological Office, 173 London, 1989.

Berlage, H. P., The Southern Oscillation, a 2-3 year fundamental oscillation of a world-wide significance, in I.U.G.G. 10th General Assembly, Rome, 1954, Ed. I. London, Scientific Proc. of the Int. Association of Meteorology, 336-345, 1955.

Berlage, H.P., Fluctuations of the general atmospheric circulation of more than one year, their nature and prognostic value, Royal Netherland Meteorological Institute, Mededeling en Verhandelingen, 69, 1957.

Black, R. X., D. A. Salstein, and R. D. Rosen, Interannual modes of variability in atmospheric angular momentum, J. Clim., 9, 2834-2849, 1996.

Box, E. P., and G. M. Jenkins, Time series analysis, forecasting and control, Holden-day, San Francisco, 1976.

Brassington, G. B., The modal evolution of the southern oscillation, Bull. Am. Meteorol. Soc., 10, 1021-1034, 1997.

Buffett, B. A., Gravitational oscillations in length of day, Geophys. Res. Lett., 23, 2279-2289, 1996.

Chao, B. F., Interannual length-of-day variation with relation with the Southern Oscillation/El Niño, Geophys. Res. Lett., 11, 541544, 1984

Chao, B. F., Length-of-day variations caused by El Niño/Southern Oscillation and quasi biennial oscillation, Science, 243, 923-925, 1989.

Dettinger, M. D., M. Ghil, C. Strong, W. Weibel, and P. Yiou, Software expedities singular-spectrum analysis of noisy time series, Eos. Trans. AGU, 76, 12,14,21, 1995a.

Dettinger, M. D., C. L. Keppenne, and M. Ghil, Interannnual and interdecadal variability in United States surface air-temperatures, 1910-1987, Clim. Change, 31, 35-66, 1995b.

DeViron, O., C. Bizouard, D. Salstein, and V. Dehant, Atmospheric torque on the Earth and comparison with atmospheric angular momentum variations, J. Geophys. Res., 104, 4861-4875, 1999.
Dickey, J. O., M. Ghil, and S. L. Marcus, Extratropical aspects of the 40-50 day oscillation in the length-of-day and atmospheric angular momentum, J. Geophys. Res., 96, 643-622, 1991.

Dickey, J. O., S. L. Marcus, and R. Hide, Global propagation of interannual fluctuations in atmospheric angular momentum, Nature, 357, 484-488, 1992.

Dickey, J. O., P. Gegout, and S. L. Marcus, Earth-Atmosphere angular momentum exchange and ENSO: the rotational signature of the 1997-98 event, Geophys. Res. Lett., 26, 2477-2488, 1999.

Djurovic, D., and P. Pâquet, The common oscillations of solar activity, the geomagnetic field, and the Earth rotation, Solar Phys., 167, 427-439, 1996.

Eubanks, T. M., Variations in the orientation of the earth, in Contributions of space geodesy to geodynamics, Eds. S. D. E., and D. L. Turcotte, 24, American Geophysical Union, Washington, D.C., 1-54, 1993.

Fraedrich, K., S. Pawson, and R. Wang, An EOF analysis of the vertical-time delay structure of the quasi-biennial oscillation, J. Atmos. Sci., 50, 3357-3365, 1993.

Gambis, D., Wavelet transform analysis of the length of the day and the El-Niño/Southern Oscillation variations at intraseasonal and interannual time scales, Ann. Geophysicae., 10, 429437, 1992.

Geller, M. A., W. Shen, M. Zhang, and W.-W. Tan, Calculations of the stratospheric quasi-biennial oscillation for time-varying wave forcing, J. Atmos. Sci., 54, 883-894, 1997.

Goswani, B. N., A multiscale interaction model for the origin of the tropospheric qbo, J. Clim., 8, 524-534, 1995.

Gray, W. M., J. D. Scheaffer, and J. A. Knaff, Hypothesized mechanism for the stratospheric QBO influence on ENSO variability, Geophys. Res. Lett., 19, 107-110, 1992.

Greiner-Mai, H., Decade variations of the Earth's rotation and geomagnetic core-mantle coupling, J. Geomagn. Geolectr., 45, 1333-1345, 1993.

Greiner-Mei, H., and H. Jochmann, Correction to "Climate variations and the Earth's rotation", J. Geodyn., 25, 1-4, 1998.

Gross, R. M., Combination of earth orientation measurements: Space94, Comb94, and Pole94, J. Geophys. Res., 101, 87298740, 1992.

Guinot, B., Astrolabe Series, Personal communication, 1996.

Gutzler, D. A., and D. E. Harrison, The structure and evolution of seasonal wind anomalies over the near-equatorial eastern and western pacific oceans, Mon. Weather Rev., 115, 169-192, 1987.

Hide, R., and J. O. Dickey, Earth's variable rotation, Science, 253, 629-637, 1991.

Holton, J. R., and R. S. Lindzen, An updated theory for the quasibiennial oscillation of the tropical stratosphere, J. Atmos. Sci., 29, 1076-1080, 1972.

Höpfner, J., Seasonal variations in length of day and atmospheric angular momentum, Geophys. J. Int., 135, 407-437, 1998.

IERS, International Earth Rotation Service, Annual Report, Observatoire de Paris, 1998.

Iijima, S., and S. Okazaki, On the biennial component in the rate of rotation of the earth, J. Geod. Soc. Japan., 12, 91, 1966.

Jochmann, H., and H. Greiner-Mai, Climate variations and the Earth's rotation, J. Geodynamics., 21, 161-176, 1996.

Jordi, C., L. V. Morrison, R. D. Rosen, D. A. Salstein, and G. Rosello, Fluctuations in the earth's rotation since 1830 from high-resolution astronomical data, Geophys. J. Int., 117, 811818, 1994.

Kang, I.-S., and K.-M. Lau, Principal modes of atmospheric circulation anomalies associated with global angular momentum fluctuations, J. Atmos. Sci., 51, 1194-1205, 1994.

Kalnay, E., M. Kanahitsu, R. Kistler, W. Collins, D. Deaven, L. Gandin, H. Iredell, S. Saha, S. White, J. Woollen, Y. Zhu, M. Chelliah, W. Ebisuzaki, W. Higgins, J. Jandwiak, K. C. Mo, C. Ropelewski, J. Wang, A. Leetma, R. Reynolds, R. Jenne, and D. Joseph, The NCEP/NCAR 40-year reanalysis project, Bull. Am. Meteorol. Soc., 77, 437-471, 1996. 
Lambeck, K., The Earth's variable rotation, Clarendon Press, Cambridge, 1980.

Landsberg, H. E., Biennial pulses in the atmosphere, Beitr. Phys. Atmos., 35, 184-194, 1962.

Landsberg, H. E., J. M. Mitchell Jr., H. L. Crutcher, and F. T. Quinlan, Surface signs of biennial atmospheric pulse, Mon. Weather. Rev., 101, 549-556, 1963.

Lau, K. M., and P. J. Sheu, Annual cycle, quasi-biennial oscillation, and southern oscillation in global precipitation, J. Geophys. Res., 93, 10975-10988, 1988.

Leroux, M., The mobile polar high: a new concept explaining present mechanism of meridional air-mass and energy exchanges and global propagation of palaeoclimatic changes, Global Planet Change, 7, 69-93, 1993.

Marcus, S. L., Y. Chao, J. O. Dickey, and P. Gegout, Detection and modeling of nontidal oceanic effects on earth's rotation rate, Science, 281, 1656-1659, 1998.

Moron, V., R. Vautard, and M. Ghil, Trends, interdecadal and interannual oscillations in global sea-surface temperatures, Clim. Dyn., 14, 545-569, 1998.

Munk, W. H., and J. F. MacDonald, The rotation of the Earth, a geophysical discussion, Cambridge University Press, Cambridge, 1960.

Naujokat, B., An update of the observed quasi-biennial oscillation of the stratospheric winds over the tropics, J. Atmos. Sci., 43, 1873-1877, 1986.

Oort, A. H., and J. J. Yienger, Observed interannual variability in the Hadley circulation and its connection to ENSO, J. Clim., 9, 2751-2766, 1996.

Press, W. H., B. P. Flannery, S. A. Teukolski, and V. A. Vetterling, Numerical Recipes: The Art of Scientific Computing, Cambridge University Press, Cambridge, 1992.

Quinn, W. H., A study of southern oscillation-related climatic activity for A.D. 622-1900 incorporating nile river flood data, in El Niño, historical and paleoclimatical aspects of the southern oscillation, Eds. H.F. Diaz, and V. Margraf, Cambridge University Press, New York, 119-149, 1992.

Quiroz, R. S., Period modulation of the stratospheric quasibiennial oscillation, Mon. Weather Rev., 109, 665-674, 1981.

Quiroz, R. S., Relationships among the stratospheric and tropospheric zonal flows and the Southern Oscillation, Mon. Weather. Rev., 111, 143-154, 1983.

Rasmusson, E. M., X. Wang, and C. F. Ropelewski, The biennial component of ENSO variability, J. Mar. Syst., 1, 71-96, 1990.

Reed, R. J., W. J. Campbell, L. A. Rasmussen, and D. G. Rogers, Evidence of downward-propagating annual wind reversal in the equatorial stratosphere, J. Geophys. Res., 66, 813-818, 1961.

Ropelewski, C. F., M. S. Halpert, and X. Wang, Observed tropospheric biennial variability and its relationship to the Southern Oscillation, J. Clim., 5, 594-614, 1992.

Rosen, R. D., The axial momentum balance of earth and its fluid envelope, Surv. Geophys., 14, 1-29, 1993.

Rosen, R. D., and D. A. Salstein, Variations in atmospheric angular momentum on global and regional scales and length of day, J. Geophys. Res., 88, 5451-5470, 1983.

Salstein, D. A., Angular momentum during the 1997-98 event, in IERS Technical note 26: The impact of El Nino and other lowfrequency signals on Earth rotation and global Earth system parameters, Eds. D. Salstein, B. Kolaczek, and D. Gambis, Observatoire de Paris, Paris, 13-16, 1999.

Salstein, D. A., and R. D. Rosen, Earth rotation as a proxy for interannual variability in atmospheric circulation, 1860-present, J. Clim. Appl. Meterol., 25, 1870-1877, 1986.

Salstein, D. A., and R. D. Rosen, Global momentum and energy parameters from reanalyses, in WRCP Fisrt International Conference on Reanalyses, Silver Spring, MD, Ed. WMO, 286-289, 1997
Salstein, D. A., D. M. Kann, A. J. Miller, and R. D. Rosen, The sub-bureau for atmospheric angular momentum of the international earth rotation service: a meteorological data center with geodetic applications, Bull. Am. Meteorol. Soc., 14, 67-80, 1993.

Sasi, M. N., A relationship between equatorial lower stratospheric QBO and El Niño, J. Atmos. Terr. Phys., 56, 1563-1570, 1994.

Sasi, M. N., and B. V. Krishna Murthy, A study of quasi-biennial oscillation in the tropical stratosphere, J. Atmos. Terr. Phys., 53, 1173-1180, 1991

Starr, V. P., An essai on the general circulation of the Earth's atmosphere, J. Meteorol., 5, 39-43, 1948.

Stefanick, M., Interannual atmospheric angular momentum variability 1963-1973 and the southern oscillation, J. Geophys. Res., 87, 428-432, 1982.

Stephenson, F. R., and L. V. Morrison, Long-term fluctuations in the Earth's rotation: 700 BC to AD 1990, Phil. Trans. R. Soc. London, 351, 165-202, 1995.

Swinbank, R., and A. O'Neill, Quasi-biennial and semi-annual oscillations in equatorial wind fields constructed by data assimilation, Geophys. Res. Lett., 21, 2099-2102, 1994.

Takahashi, M., Simulation of the stratospheric quasi-biennial oscillation using a general circulation model, Geophys. Res. Lett., 23, 661-664, 1996.

Torrence, C., and G. P. Compo, A practical guide to wavelet analysis, Bull. Am. Meteorol. Soc., 79, 61-78, 1998.

Trenberth, K. E., Atmospheric quasi-biennial oscillations, Bull. Am. Meteorol. Soc., 108, 1370-1292, 1980.

Trenberth, K., and T. J. Hoar, The 1990-1995 El Niño southern oscillation event; longest on record, Geophys. Res. Lett., 23, 57-60, 1996.

Vautard, R., and M. Ghil, Singular spectrum analysis in nonlinear dynamics, with application to paleoclimatic time series, Physica $D, \mathbf{3 5}, 395-424,1989$.

Vautard, R., P. Yiou, and M. Ghil, Singular spectrum analysis: a toolkit for chaotic time series, Physica D., 38, 74-95, 1992.

Veryard, R. G., and R. A. Ebdon, Fluctuations in tropical stratospheric winds, Meteorol. Mag., 90, 125-143, 1961.

Vondrak, J., The rotation of the Earth between 1955.5 and 1976.5, Stud Geophys. Geod., 21, 107-117, 1977.

Wahr, J. M., The Earth's rotation, Ann. Rev. Earth Planet. Sci., 16, 231-249, 1988.

Wahr, J. M., and A. H. Oort, Friction- and mountain-torque estimates from global atmospheric data, J. Atmos. Sci., 41, 190204, 1984

Wallace, J. M., General circulation of the tropical lower stratosphere, Rev. Geophys. Space. Phys., 11, 191-222, 1973.

Wang, B., and Y. Wang, Temporal structure of the Southern Oscillation as revealed by waveform and wavelet, J. Clim., 9, 1586-1598, 1996.

Weickmann, K. M., G. N. Kiladis, and P. D. Sardeshmukh, The dynamics of intraseasonal atmospheric angular momentum oscillations, J. Atmos. Sci., 54, 1445-1461, 1997.

$\mathbf{X u}$, J., and H. v. Storch, Predicting the state of Southern Oscillation using principal oscillation pattern analysis, J. Clim., 3, 1316-1329, 1990.

$\mathbf{X u}, \mathbf{J} .-\mathbf{S}$. , On the relationship between the stratospheric quasibiennial oscillation and the tropospheric southern oscillation, J. Atmos. Sci., 49, 725-734, 1992.

Yasunari, T., Zonally propagating modes of the global east-west circulation associated with the Southern Oscillation, J. Meteorol. Soc. Japan., 63, 1013-1029, 1985.

Yasunari, T., A possible link of the QBOs between the stratosphere, troposphere and sea surface temperature in the tropics, J. Meteorol. Soc. Japan., 67, 483-493, 1989.

Zhang, Y., J. M. Wallace, and D. S. Battisti, ENSO-like interdecadal variability: 1900-93, J. Clim., 10, 1004-1020, 1997. 